\title{
Quimiorreceptores arteriales: mecanismos celulares y moleculares de las funciones adaptativa y homeostática del cuerpo carotídeo
}

\author{
C. González ${ }^{\mathrm{a}}$, A. Rocher ${ }^{\mathrm{a}}$, P. Zapata ${ }^{\mathrm{b}}$
}

\author{
ARTERIAL CHEMORECEPTORS: CELLULAR AND MOLECULAR MECHANISMS \\ IN THE ADAPTATIVE AND HOMEOSTATIC FUNCTION OF THE CAROTID BODY
}

\begin{abstract}
Summary. The carotid body is a sensory chemoreceptor organ located in the vicinity of the carotid bifurcation. Structurally it is composed of cell clusters formed by chemoreceptor and supporting cells. The sensory nerve endings of the carotid sinus nerve penetrate the clusters to synapse with chemoreceptor cells. The carotid body plays an important role in the control of ventilation during hypoxia, hypercapnia and acidosis. Hypoxia and other natural stimuli are detected by chemoreceptor cells which upon stimulation increase their rate of release of neurotransmitters. Neurotransmitters in turn increase the action potential frequency in the carotid sinus nerve which via its central projections to the brainstem activates ventilation. This review is devoted to the cellular aspects of the function of this chemoreceptor organ. From a briefdescription of the complex structure of the carotid body, we go to present a summary of the main prevailing theories concerning the transduction mechanisms for hypoxic and acidic/ hypercapnic stimuli, with special emphasis on the electrical properties of cultured chemoreceptors cells. A special attention is provided to the possible significance of reactive oxygen species as mediators of the hypoxic transduction cascade. The neurotransmission between chemoreceptor cells and the sensory nerve endings is also covered in certain detail. After a brief historical presentation of the theories of communication between these two structures, we examine, following the classical criteria of neurotransmission, the functional significance of acetylcholine, dopamine, substance P and otherneurotransmitters known to be present in chemoreceptor cells. [REV NEUROL 2003; 36: 239-54]
\end{abstract}

Key words. Carotid body. Dopamine. Hypoxia. $K^{+}$channels. Neurotransmission. Sensory transduction.

\section{INTRODUCCIÓN}

La respiración celular, en sentido amplio, engloba todos los procesos que posibilitan que el $\mathrm{O}_{2}$ oxide los nutrientes para obtener energía. En los animales superiores, las células obtienen el $\mathrm{O}_{2}$ del medio interno. En los animales terrestres, el aprovisionamiento de $\mathrm{O}_{2}$ del medio interno ocurre en una serie de etapas que son: el bombeo de aire rico en $\mathrm{O}_{2}$ desde la atmósfera a los alvéolos, la difusión del $\mathrm{O}_{2}$ de los alvéolos a la sangre, su unión a la hemoglobina, la circulación de la sangre rica en $\mathrm{O}_{2}$ hasta los capilares de todo el organismo, la difusión del $\mathrm{O}_{2}$ de la sangre al medio interno, al interior de las células y a las mitocondrias donde, sensu estricto, tiene lugar la respiración celular. De esta definición amplia de la respiración se deduce que la hipoxia, definida como cualquier situación en la que la utilización de $\mathrm{O}_{2}$ por las células es insuficiente para mantener sus funciones, puede resultar de:

- Un aprovisionamiento inadecuado de $\mathrm{O}_{2}$ a la sangre (hipoxia hipóxica).

- Una capacidad disminuida de la sangre para captar $\mathrm{O}_{2}$ (hipoxia anémica).

- Un flujo insuficiente de sangre para llevar el $\mathrm{O}_{2}$ hasta los capilares (hipoxia de estasis).

Recibido: 14.01.03. Aceptadotras revisión externa sinmodificaciones: 14.01.03.

${ }^{a}$ Departamento de Bioquímica y Biología Molecular y Fisiología. Instituto de Biología y Genética Molecular (IBGM). Facultad de Medicina. Universidad de Valladolid-CSIC. Valladolid, España. ${ }^{b}$ Laboratorio de Neurobiología. P. Universidad Católica de Chile. Santiago, Chile.

Correspondencia: Prof. Constancio González. Departamento de Bioquímica y Biología Moleculary Fisiología. Facultad de Medicina. Universidad de Valladolid.E-47005 Valladolid. Fax: +34983423 588. E-mail: constanc@ibgm.uva.es

Agradecimientos. A M. ${ }^{a}$ de los Llanos Bravo, por su ayuda.

Trabajo financiado por la DGICYT, proyecto BFI2001-1713. El trabajo de P. Zapata es financiado por el proyecto 1010951 de CONICYT.

(C) 2003, REVISTA DE NEUROLOGÍA
- Una incapacidad de las células para usar el $\mathrm{O}_{2}$ a la velocidad adecuada (hipoxia histotóxica).

En un organismo sano, la única hipoxia que puede ocurrir de forma natural es la hipoxia hipóxica debida a la disminución de la presión barométrica, tal como ocurre a grandes alturas. El resto de las hipoxias son patológicas [1].

Los animales superiores poseen mecanismos de regulación que tienden a prevenir o minimizar cualquier tipo de hipoxia y que usan como efectores a los aparatos respiratorio y circulatorio. Los quimiorreceptores del cuerpo carotídeo (CC) o glomus caroticum detectan la presión arterial de $\mathrm{O}_{2}\left(\mathrm{PaO}_{2}\right)$ e inician, cuando ésta disminuye, reflejos encaminados a aumentar el bombeo de aire rico en $\mathrm{O}_{2}$ desde la atmósfera a los alvéolos. En este contexto, se dice que los CC (con alguna posible contribución de los cuerpos aórti$\cos$ ) tienen una función adaptativa, ya que la hiperventilación que desencadenan al disminuir la $\mathrm{PaO}_{2}$ hace posible que los animales sanos, incluido el hombre, realicen las funciones vitales de forma adecuada (esto es, se adapten) a altitudes con presiones barométricas de hasta unos $350 \mathrm{mmHg}$. La gran sensibilidad (umbral bajo y ganancia alta, en términos fisiológicos) de los $\mathrm{CC}$ a la hipoxia se acompaña de una gran resistencia a sus efectos deletéreos, lo que llevó a denominarlo 'ultimum moriens' [2]. Experimentalmente, se puede comprobar que los impulsos nerviosos que se generan en el CC y que se registran en el nervio del seno carotídeo (NSC), persisten por lo menos media hora después de muerto el animal. Por otra parte, son las descargas de los CC las que mantienen la respiración y, por ende, la vida, en animales profundamente anestesiados: éstos dejan de respirar al suministrarles $\mathrm{O}_{2}$ en vez de aire [3].

Además, los $\mathrm{CC}$ detectan la $\mathrm{PCO}_{2}$ y el pH arteriales: cuando la $\mathrm{PaCO}_{2}$ o la concentración de $\mathrm{H}^{+}$aumentan, los $\mathrm{CC}$ (junto con los quimiorreceptores centrales y alguna contribución de los cuerpos aórticos) inician una hiperventilación refleja que tiende a descargar el exceso de $\mathrm{CO}_{2}$ y de $\mathrm{H}^{+}$a la atmósfera; esto es, los $\mathrm{CC}$ 
tienen una importante función homeostática en relación con el $\mathrm{CO}_{2}$ y los $\mathrm{H}^{+}$. Los $\mathrm{CC}$ también detectan cambios en la temperatura y osmolaridad del fluido que les perfunde (sangre in vivo y solución salina in vitro [4]), pero el significado funcional de estas detecciones no está bien definido a nivel sistémico.

El objetivo de esta revisión es presentar la estructura y la fisiología celular del CC, esto es, el conjunto de los mecanismos celulares y moleculares que operan en el CC y que sustentan la función adaptativa y homeostática del órgano. En un segundo artículo, que aparecerá en un número próximo [5], describiremos la fisiología sistémica del CC, esto es, las funciones adaptativa y homeostática del CC propiamente dichas. En ningún caso pretendemos hacer un tratamiento exhaustivo de la literatura. Un tratamiento en detalle de cualquier aspecto de la fisiología del CC puede encontrarse en las referencias 6 y 7 .

\section{ORGANIZACIÓN ESTRUCTURAL Y FUNCIONAL DEL CUERPO CAROTÍDEO Localización, estructura y ultraestructura del cuerpo carotídeo}

El CC es un órgano par (Fig. 1a) situado en las proximidades de las bifurcaciones carotídeas y que en el hombre adulto tiene en torno a $2 \mathrm{~mm}$ de diámetro. Fue descrito en autopsias en humanos por Albrecht von Haller y su discípulo Hartwig Taube, que consideraron al CC un microganglio vegetativo (gangliumminutium); esta primera descripción fue publicada en la disertación doctoral de Taube en 1743 [8]. Luscka [9] consideró al CC, en razón de su estructura, una glándula (glandula intercarotica). Fernando de Castro [10] comprobó, en 1926, que la inervación simpática que recibe el CC inerva los vasos, y no el parénquima; en 1928, mediante experimentos de degeneración walleriana, demostró que la inervación del parénquima glómico, que proviene del ganglio petroso vía glosofaríngeo y NSC o de Hering, era sensorial, y no secretomotora. Por ello, De Castro concluye que el CC no podía ser ni un ganglio ni una glándula, sino un 'órgano sensorial especial destinado a detectar ciertas modificaciones cualitativas de la sangre [...] y no variaciones en la presión sanguínea, función que, tal vez por acción refleja, tendría su repercusión sobre la actividad funcional de otros órganos' [11]. Heymans et al, en Gante, demostraron que la hiperventilación producida por la hipoxia y la acidosis tenía su origen en el CC [12,13].

Los CC están formados por islotes o nidos celulares, que constituyen el parénquima glómico, y que están rodeados por tabiques de tejido conectivo. Los nidos celulares están formados por dos tipos celulares, las células glómicas, quimiorreceptoras o tipo I, y las células sustentaculares, capsulares o tipo II (Fig. 1b). Las primeras son redondas u ovoides, poseen un citoplasma rico en vesículas de núcleo denso y tienden a ocupar el centro de los islotes; las segundas son aplanadas, no poseen especializaciones citoplásmicas y se sitúan en la periferia de los islotes celulares. Las células tipo II son consideradas células de soporte de naturaleza neuroglial.

Cada CC recibe irrigación desde la arteria glómica, que, frecuentemente, emerge de la carótida externa. Hay vasos capilares tortuosos en torno a los cuales se organizan los nidos celulares, pero también gran abundancia de capilares rectos y algunas anastomosis arteriovenosas. Las vénulas se reúnen en la periferia del CC para formar un plexo venoso periglómico. Los lechos vasculares (Fig. 1, c y d) ocupan no menos del 25-30\% de la superficie de las secciones histológicas del CC [14-16], lo que excede por un factor de 5 a 6 la densidad media de capilares de la corteza cerebral.
Esto permite que el CC tenga un flujo sanguíneo de 1,4-2,0 L/100 g de tejido/min $[17,18]$, que excede igualmente por un factor de 6 a 10 el flujo cerebral medio [19].

Según describiera De Castro [11], las células parenquimatosas del CC (células glómicas o quimiorreceptoras) reciben inervación sensorial a través del NSC. Las fibras sensoriales provienen de neuronas que se asientan en el ganglio glosofaríngeo inferior, petroso o ganglio de Andersch (muy pocas fibras provienen del ganglio glosofaríngeo superior o de Ehrenritter [20]), y llegan al CC a través del NSC, para penetrar en los islotes celulares y formar sinapsis con las células quimiorreceptoras (Fig. 1b). Desde el punto de vista ultraestructural, las terminaciones nerviosas sensoriales son polimorfas (cálices envolventes, botones, varicosidades en passant...; [21]). Existen contactos entre las terminaciones y las células en los que las especializaciones presinápticas (proyecciones densas, acumulaciones de vesículas) se encuentran en la célula glómica y otros en los que se encuentran en la terminación nerviosa; hay contactos entre una misma célula y una terminación en los que la polarización funcional aparente tiene una dirección dada en una zona, mientras que en otra zona adyacente tiene sentido opuesto, lo que se ha interpretado como sinapsis recíprocas [22, 23]. Además de la inervación sensorial a las células glómicas y simpática a los vasos, al CC llega inervación parasimpática procedente de neuronas presentes en la superficie del CC, donde forman microganglios, y de neuronas dispersas a lo largo del NSC y en la entrada del NSC en el glosofaríngeo [10]. Estas fibras son nitrérgicas [24]; controlan el flujo sanguíneo al CC y, a su través, la actividad funcional del CC.

Las células glómicas poseen una gran variedad de sustancias que cumplen el papel de neurotransmisores en otras estructuras. Contienen dopamina (DA) y noradrenalina (NA), acetilcolina (ACh), péptidos opioides, ATP y otros muchos neurotransmisores peptídicos (péptido atrial natriurético, endotelina, sustancia $\mathrm{P}$, péptido intestinal vasoactivo, neurotensina, galanina, colecistoquinina...), probablemente en un patrón de coalmacenamiento complejo [ver 23]. Existen varias contradicciones aparentes en la neuroquímica del CC. Por ejemplo, varios autores encuentran a nivel inmunocitoquímico y bioquímico que las células quimiorreceptoras poseen sustancia $\mathrm{P}$ [ver 25,26] y, sin embargo, las células glómicas no poseen ARNm capaz de codificar para sustancia $\mathrm{P}$ o neuroquinina A (ARNm para preprotaquiquinina) [27-29]. Dos laboratorios han encontrado ACh en el CC de gato y rata en concentraciones similares con cromatografía de gases/espectrometría de masas [30, 31]; en cambio, nosotros no hemos obtenido síntesis de ACh ni actividad colinacetiltransferasa (ChAT) en el CC de gato, mientras que ambos parámetros, medidos simultáneamente en el ganglio cervical superior, coincidían con los existentes en la literatura [32]. También hay discrepancias en los niveles publicados de DA y, en especial, de NA y, por tanto, en los cocientes DA/NA; el desigual grado de disección del CC y la proximidad del ganglio cervical superior y de los nervios ganglioglomerulares ricos en NA explican estas variaciones.

Para una revisión crítica de la estructura normal del CC, véase Verna [23].

\section{Organización funcional: el CC como un receptor sensorial secundario}

Sobre la base de esta organización estructural que De Castro [11] captó de forma magistral, el mismo autor propuso [11,33] una organización funcional del CC en la que las células glómicas o 


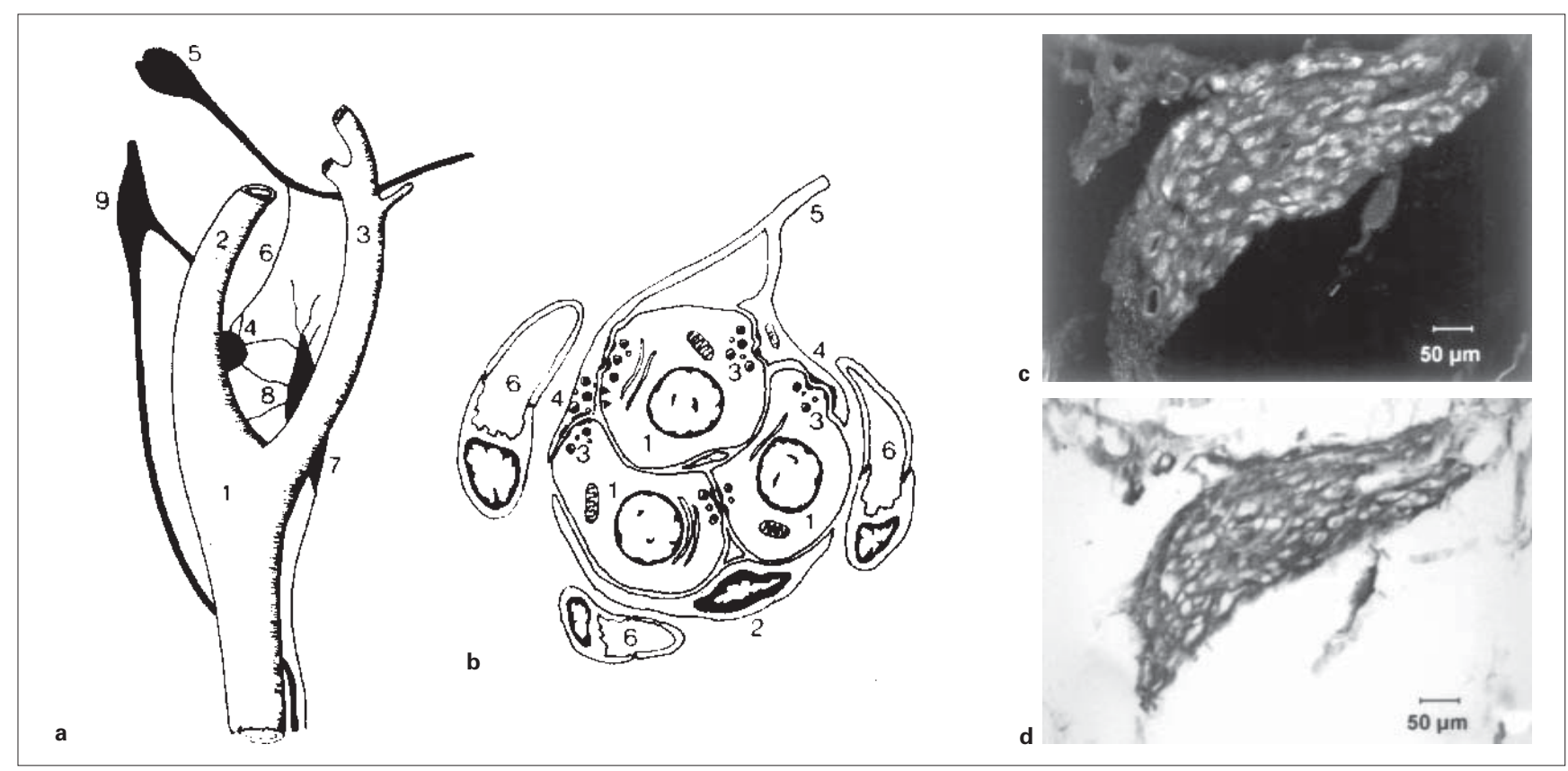

Figura 1. Localización y estructura del cuerpo carotídeo. a) Región de la bifurcación carotídea derecha de conejo: 1. Seno carotídeo; 2 . Carótida interna; 3. Carótida externa. 4) Cuerpo carotídeo (en el conejo asienta sobre la carótida interna, a veces formando como un manguito); 5 . Ganglio petroso; 6 . Nervio del seno carotídeo; 7. Tronco simpático del cuello y ganglio cervical superior; 8. Nervios ganglioglomerulares; 9. Ganglio sensorial del vago (ganglio nodoso). b) Esquema de la estructura del cuerpo carotídeo: 1. Células glómicas, quimiorreceptoras o tipo I; 2. Célula sustentacular o tipo II; 3 . Vesículas sinápticas, de tamaño y densidad heterogéneos; 4. Terminaciones nerviosas sensoriales (en la terminación de la izquierda puede observarse la estructura que correspondería a una sinapsis recíproca); 5. Fibra sensorial; 6. Capilares que rodean el nido o islote celular. c) Demostración inmunocitoquímica de tirosina hidroxilasa en una sección próxima al ecuador de un cuerpo carotídeo de rata. Sólo las células quimiorreceptoras que contienen y sintetizan catecolaminas son positivas para el enzima. Las terminaciones simpáticas no se distinguen a esta amplificación. d) La misma sección que en c), pero contrateñida con hematoxilina-eosina para poder visualizar la gran densidad de vasos. a) y b), tomado de González C, Almaraz L, Obeso A, Rigual R. Oxygen and acid chemoreception in the carotid body chemoreceptors. Trends Neurosci 1992; 15: 146-53, con permiso de Elsevier Science. c) y d), cortesía de la Dra. A. Obeso.

quimiorreceptoras captarían por su polo vascular los estímulos presentados por la sangre, gracias a la densa red capilar, y por su polo nervioso, y gracias a productos de su metabolismo, activarían a las terminaciones de las fibras aferentes para iniciar los reflejos. Sin embargo, el hallazgo de vesículas sinápticas en las terminaciones nerviosas que contactan las células glómicas llevó a proponer a Biscoe y sus colaboradores que estas terminaciones eran eferentes, secretomotoras [34], y que las células glómicas formarían parte de un mecanismo central de control de la actividad quimiorreceptora [35], que a su vez estaría sustentada por unas fibras sensoriales descritas ad hoc en el propio laboratorio de Biscoe. La naturaleza aferente de las terminaciones que sinaptan con las células quimiorreceptoras quedó restablecida al confirmarse que no degeneraban tras la sección intracraneal de las raíces del glosofaríngeo, mientras que sí lo hacían cuando se seccionaba distalmente al ganglio petroso [36]. Funcionalmente, hay muchos estudios que demuestran la necesidad de la integridad de las células glómicas y de su relación sináptica con las terminaciones sensoriales para que el CC exhiba función quimiorreceptora:

- La hiperventilación refleja en respuesta a la hipoxia desaparece en pacientes a los que se han extirpado los CC [37-40]. Los reflejos ventilatorios a la hipoxia también desaparecen en las ratas tras resección bilateral de los CC [41].

- La actividad quimiosensorial desaparece cuando se destruye el CC por criocoagulación [42] o por isquemia [43]. El parénquima es reemplazado por un tejido cicatricial, donde se encuentran como terminaciones libres las otrora terminaciones quimiorreceptoras.
- Tras la sección del NSC, la función quimiorreceptora se restablece al mismo tiempo que las fibras nerviosas en regeneración reinervan las células glómicas [44].

- Se consigue la aparición de actividad quimiosensorial en nervios foráneos que reinervan al CC in situ $[14,45]$ o a transplantes de CC [46].

- Puede registrarse actividad quimiosensorial en neuronas cultivadas de ganglios nodoso y petroso sólo cuando se cocultivan con células glómicas de CC [47,48].

- La única respuesta a la hipoxia, y sólo a hipoxias intensas, que expresan las neuronas del petroso que proyectan al CC es una disminución de su excitabilidad [49].

En suma, estas observaciones indican que las neuronas quimiosensoriales, separadas de las células glómicas, son incapaces de detectar la hipoxia; requieren un contacto estrecho con las células glómicas para cumplir esta función [50]. Por tanto, el CC es un receptor sensorial secundario [51] en el que las células glómicas detectan los estímulos naturales y, merced a una etapa de neurotransmisión, comandan la actividad de las terminaciones sensoriales del NSC.

\section{FISIOLOGÍA CELULAR DEL CUERPO CAROTÍDEO \\ Transducción sensorial en el CC: mecanismos de detección de los estímulos y de activación de las células quimiorreceptoras Aspectos históricos: hipótesis metabólica y ácida}

De las teorías propuestas para explicar el proceso de quimiorrecepción en el CC, la que consiguió mayor difusión fue la teoría 
metabólica propuesta por Anichkov y Belen'kii [52] en estos términos: '[...] los venenos que bloquean la respiración tisular o la hacen inútil determinan que la síntesis de enlaces de alta energía sea inferior a su degradación, y en consecuencia producen un balance energético negativo en el tejido quimiorreceptor. Por tanto, debe considerarse que la excitación de los quimiorreceptores producida por dichos venenos, que son de naturaleza química muy variada, es la reacción a un balance energético negativo. No hay duda de que la hipoxia, el estímulo fisiológico adecuado para los quimiorreceptores del cuerpo carotídeo, produce un desplazamiento negativo en el balance energético. [...] Es por tanto obvio que el mecanismo íntimo de la excitación hipóxica de los quimiorreceptores tiene que ser similar al mecanismo de excitación producido por los venenos que abolen la respiración celular o la hacen inútil'.

La primera crítica a la hipótesis metabólica surgió al considerar que el flujo sanguíneo y el consumo de $\mathrm{O}_{2}$ medidos $(1,4-2,0 \mathrm{~L} / 100 \mathrm{~g}$ de tejido/min y $9 \mathrm{~mL} / 100 \mathrm{~g}$ de tejido/min, respectivamente [17]) aseguraban una $\mathrm{PO}_{2}$ en la sangre venosa del CC, y por tanto en el tejido glómico, muy superior a la requerida para mantener normal el flujo de electrones en la cadena respiratoria incluso a $\mathrm{PaO}_{2}$ sistémicas muy inferiores al umbral de activación del CC [53,54]. La medición de niveles de ATP en el CC ha demostrado que niveles de hipoxia que producen activación intensa del $\mathrm{CC}$ no disminuyen los niveles de ATP o los reducen muy moderadamente $[55,56]$. Tampoco resultó cierto que el nexo común en la capacidad de los venenos metabólicos para activar al CC fuera la disminución del ATP: a concentraciones que producen activación comparable de las células quimiorreceptoras (liberación de DA) y de la descarga en el NSC, el cianuro redujo en $45 \%$ los niveles de ATP, mientras que el dinitrofenol y el CCCP no los modificaron; la acción desacoplante de los dos últimos agentes se compensó con un aumento del consumo de glucosa [57,58]. Finalmente, hemos de mencionar que ya Krylov y Anichkov [59] encontraban que la hipótesis metabólica no explicaba la sensibilidad del CC al ácido.

La otra gran hipótesis clásica es la hipótesis ácida, propuesta inicialmente por Winder en 1937 [60]. Winder encontró que ciertas dosis de yodoacetato, un inhibidor de la glicólisis, abolían la respuesta a la hipoxia y no a los estímulos ácidos. Postuló que las terminaciones sensoriales serían receptores de $\mathrm{H}^{+}$, ya que el bloqueo de la producción de ácido láctico eliminaba la actividad del CC, mientras se conservaba la sensibilidad del órgano quimiorreceptor a los cambios directos de la concentración de $\mathrm{H}^{+}$. La hipoxia estimularía a estos receptores porque, al deprimir la oxidación de glucosa, activaría compensatoriamente la glicólisis y la producción de lactato. Los hallazgos de Winder no pudieron confirmarse, pero la idea de la unificación de los mecanismos de detección de los estímulos hipóxico y ácido fue retomada por Torrance, quien, entre 1974 y 1981 [61-63] propuso dos enmiendas distintas de la hipótesis ácida con unos postulados que no pudieron verificarse [64; ver 65]. Sin embargo, en el contexto de la hipótesis ácida, se encontró que la anhidrasa carbónica es responsable de los componentes dinámicos de la respuesta al $\mathrm{CO}_{2}$ (overshoot y undershoot a la presentación y retirada del estímulo), lo que indica que la señal detectada en el CC es la concentración de $\mathrm{H}^{+}[63,66]$. Dado que la enzima se localiza en el interior de las células quimiorreceptoras [67], la respuesta al ácido se generaría en las células, aunque no podamos excluir cierta sensibilidad de las terminaciones sensoriales a $\operatorname{los} \mathrm{H}^{+}$.

\section{Mecanismos de transducción del estímulo hipóxico}

En 1977, González y Fidone [68] demostraron por primera vez, con medidas directas, que la hipoxia aumenta la liberación de DA en CC aislados. Dado que esta catecolamina se encuentra almacenada casi con exclusividad en las células quimiorreceptoras, el hallazgo implicaba que dichas células respondían a la hipoxia. En una serie amplia de estudios, Fidone et al [69-74] caracterizaron las enzimas involucradas en la síntesis, el propio proceso de síntesis y la liberación de catecolaminas (CA) en el CC de conejo, y encontraron que la hipoxia inducía liberación de DA en relación directa con su intensidad, y que la liberación inducida era dependiente de $\mathrm{Ca}^{2+}$. Idénticas observaciones se obtuvieron en el CC de gato [75], rata [76] y ratón [26]. De otro lado, Almaraz et al [77] demostraban en 1986 que el alto $\mathrm{K}^{+}$extracelular inducía liberación de DA de forma dependiente de $\mathrm{Ca}^{2+}$, y Obeso [57] demostraba que la liberación inducida por alta concentración de $\mathrm{K}^{+}$y por hipoxia era sensible a dihidropiridinas antagonistas (y agonistas) de canales de $\mathrm{Ca}^{2+}$, mientras que la liberación inducida por los estímulos ácidos, aun siendo dependiente de $\mathrm{Ca}^{2+}$, era insensible a dihidropiridinas [78]. En otro frente, Rocher [79-81] demostró que la veratridina, un activador de canales de $\mathrm{Na}^{+}$dependientes de voltaje, inducía liberación de DA de forma dependiente de $\mathrm{Na}^{+}$y $\mathrm{Ca}^{2+}$ y sensible a tetrodotoxina (TTX), y que la liberación inducida por la hipoxia es parcialmente sensible a TTX mientras que la inducida por estímulos ácidos no lo es. Finalmente, en estudios del metabolismo del CC con la técnica de la 2-deoxiglucosa in vitro en combinación con ${ }^{14} \mathrm{C}$-glucosa, encontramos que la hipoxia activa la glicólisis y la oxidación de glucosa y que este aumento es sensible a ouabaina [82,83]. Esto indicaría que la hipoxia activa la bomba de $\mathrm{Na}^{+}$, probablemente porque despolarice las células quimiorreceptoras con un aumento de la concentración intracelular de $\mathrm{Na}^{+}$[84].

En su conjunto, estas observaciones sugerían fuertemente que la hipoxia despolarizaba las células quimiorreceptoras y promovía la activación de canales de $\mathrm{Na}^{+}$y $\mathrm{Ca}^{2+}$ dependientes de voltaje, así como la liberación exocitótica de neurotransmisores. En un intento de verificación directa de la despolarización pusimos a punto un cultivo primario de células quimiorreceptoras de conejo [ver 85] y, en colaboración con López-Barneo, comprobamos la naturaleza excitable de las células quimiorreceptoras y descubrimos el primer canal iónico regulable por la $\mathrm{PO}_{2}$ : la disminución de la $\mathrm{PO}_{2}$ produce una inhibición reversible de una corriente de $\mathrm{K}^{+}$ transitoria del tipo $\mathrm{I}_{\mathrm{A}}[86,87]$. Nuestra observación se extendió a células quimiorreceptoras de rata, en las que se han descrito como sensibles a la $\mathrm{PO}_{2}$ el canal de $\mathrm{K}^{+}$dependiente de $\mathrm{Ca}^{2+}$ de alta conductancia $\left(\right.$ maxi-K $\mathrm{K}^{+}$) [88-90] y un canal leaky de $\mathrm{K}^{+}$, presumiblemente el TASK-1 [91-93]; en las células quimiorreceptoras de gato la corriente de $\mathrm{K}^{+}$sensible a la hipoxia es del tipo rectificador tardío [94]. Estos hallazgos han constituido la base del modelo de membrana de transducción del estímulo hipóxico propuesto por nosotros en 1992 (Fig. 2) [95].

$\mathrm{Si}$ bien el modelo de membrana tiene plena vigencia, hay varios aspectos del mismo no satisfactoriamente resueltos:

1. Cómo las células detectan la $\mathrm{PO}_{2}$.

2. Cómo se acoplarían a los canales de $\mathrm{K}^{+}$los posibles mecanismos de detección.

3. Cuál es la identidad molecular de los canales de $\mathrm{K}^{+}$sensibles a la $\mathrm{PO}_{2}$.

Mecanismo de detección de la $\mathrm{PO}_{2}$. Existen dos grandes líneas de pensamiento. En registros whole cell de células quimiorrecepto- 


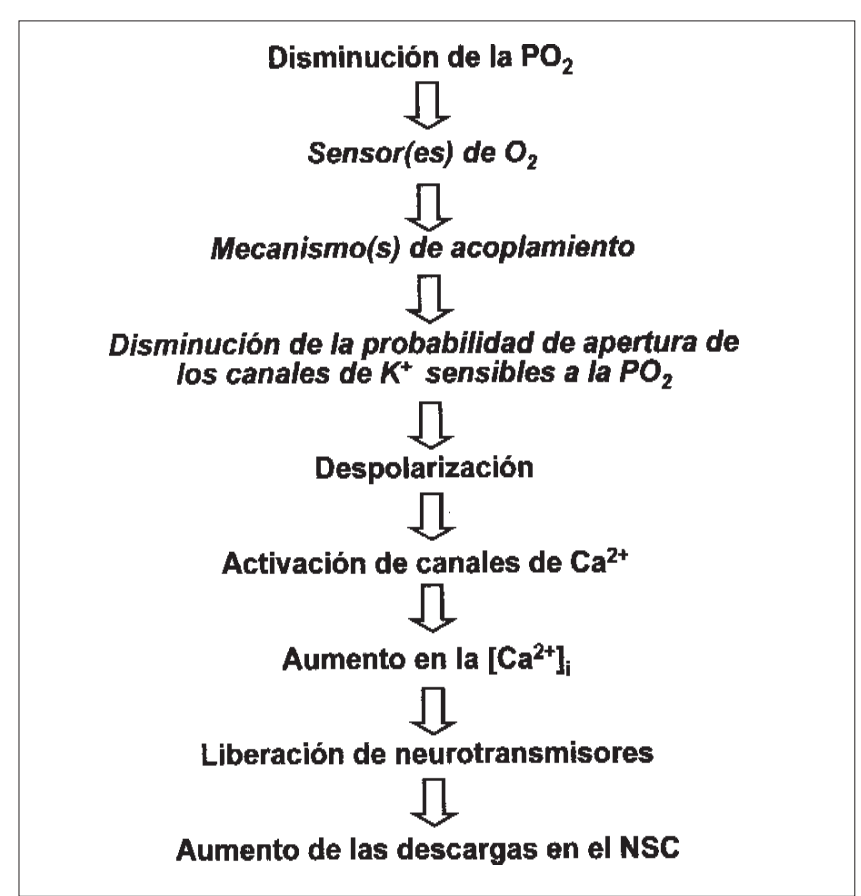

Figura 2. Modelo de membrana de transducción del estímulo hipóxico en el cuerpo carotídeo. Los aspectos menos caracterizados en el modelo aparecen en cursiva. NSC: nervio del seno carotídeo.

ras de conejo, López-López y González [96] encontraron que el CO prevenía y revertía el efecto de la hipoxia sobre la corriente de $\mathrm{K}^{+}$. Lo mismo ocurre en corrientes sensibles al $\mathrm{O}_{2}$ obtenidas en células HEK por cotransfección de subunidades Kv $\beta 1.2$ y Kv $\alpha 4.2$ [97].Y, finalmente, hemos observado que la disminución de la probabilidad de apertura $(\mathrm{Po})$ del maxi-K $\mathrm{K}^{+}$producida por la hipoxia en parches inside out aislados de células quimiorreceptoras de rata es revertida por CO [90; ver también referencias en 98,99]. Dado que en parches aislados de células de conejo la hipoxia también disminuye la Po del canal de $\mathrm{K}^{+}$sensible a la hipoxia [100], podríamos concluir que: a) La capacidad de detectar la $\mathrm{PO}_{2}$ es una propiedad intrínseca de la membrana celular o de algún componente citoplásmico íntimamente asociado a ella.b) La capacidad de detectar la $\mathrm{PO}_{2}$ no estaría asociada a actividades enzimáticas, ya que el $\mathrm{CO}$ no puede substituir al $\mathrm{O}_{2}$ como sustrato. c) Una hemoproteína que, al disminuir la $\mathrm{PO}_{2}$, se desaturara y cambiara de conformación (como la hemoglobina), y que 'transmitiera' dicho cambio conformacional al canal de $\mathrm{K}^{+}$para disminuir su Po, podría representar el sensor de $\mathrm{O}_{2}$ : el CO podría prevenir y revertir el efecto de la hipoxia sobre los canales de $\mathrm{K}^{+}$ uniéndose al lugar de unión del $\mathrm{O}_{2}$ (como en la hemoglobina).

La segunda línea de pensamiento implica a las especies reactivas de $\mathrm{O}_{2}$ (ROS) como reguladores de la Po de los canales de $\mathrm{K}^{+}$. Los ROS, actuando directamente sobre residuos oxidables de los propios canales (e.g., grupos sulfhidrilos de cisteínas o puentes tioéter de la metionina), o alterando el potencial redox de las células (e.g., disminuyendo el cociente GSH/GSSG [101]) podrían conducir a disminuciones de la Po, como lo hace la hipoxia. Existen dos propuestas: los ROS relevantes son de origen mitocondrial [102] o son producidos a nivel de alguna de las múltiples isoformas de NADPH oxidasa [103-105] que pudiera existir en el CC. Sin embargo, no sabemos si la hipoxia (de una intensidad como la que estimula el CC) aumenta o disminuye la producción de ROS, y no sabemos si es un aumento o una disminución de ROS la que produciría la disminución de la Po de los canales de $\mathrm{K}^{+}$[106-108]. Parece verosímil que el potencial redox de las células pueda modular la cinética de los canales de $\mathrm{K}^{+}$, ya que los agentes reductores y oxidantes las modifican, pero no sabemos ni la dirección de los cambios redox que produce la hipoxia ni si tienen magnitud suficiente para alterar la cinética de los canales iónicos. Hay que señalar, sin embargo, que niveles de hipoxia que activan enérgicamente el CC no modifican el cociente GSH/GSSG del CC, que es el principal determinante del potencial redox de las células; además, la modificación farmacológica de dicho cociente no modifica ni la liberación basal de DA ni la inducida por hipoxia, por $\mathrm{K}^{+}$alto o por ionomicina [109].

En cualquier caso, no podemos excluir que los dos mecanismos (y tal vez otros aún no considerados) funcionen simultáneamente. Es plausible que un sensor, o cualquier otro de los elementos de la cascada de transducción, de naturaleza proteica o hemoproteica pueda ser modificado por cambios de los niveles de ROS en compartimentos restringidos de las células. Esa modificación podría potenciar el efecto de la hipoxia o, por el contrario, frenar dicho efecto, con lo que constituiría un auténtico mecanismo de control por retroalimentación de la amplitud de la respuesta hipóxica.

Mecanismo de acoplamiento. Se desconoce el mecanismo de acoplamiento entre el posible sensor de $\mathrm{O}_{2}$ o los mecanismos de detección de $\mathrm{O}_{2}$ y los canales regulados por la $\mathrm{PO}_{2}$. Ya hemos avanzado que si el sensor fuera una hemoproteína, tal vez el mecanismo de acoplamiento fuera una transmisión alostérica del cambio conformacional del sensor al canal de $\mathrm{K}^{+}$. Si el sensor fuera un mecanismo productor de ROS (la mitocondria o una NADPH oxidasa) el acoplamiento podría ser una alteración directa de las proteínas del canal por los ROS o una alteración vía glutatión, por ejemplo por tiolación o detiolación de Prot-SH con GSH, para formar Prot-S-SG [108]. Sea cual fuere el mecanismo, un hecho parece emerger: las subunidades $\beta$ reguladoras de los canales de $\mathrm{K}^{+}$serían necesarias para el acoplamiento entre el mecanismo de detección y la subunidad conductora de los canales de $\mathrm{K}^{+}$. En efecto, en sistemas de transfección, las corrientes de $\mathrm{K}^{+}$sólo son sensibles a la hipoxia si se cotransfectan las subunidades $\alpha$ con subunidades reguladoras o si la transfección se hace a tipos celulares que expresan dichas subunidades $\beta[97,110]$. En otras palabras, las subunidades $\beta$ interaccionarían con el presunto sensor hemoproteico de $\mathrm{O}_{2}$ o serían los componentes de los canales de $\mathrm{K}^{+}$que reaccionan con los ROS (o el glutatión).

Identidad molecular del canal de $\mathrm{K}^{+}$sensible a la $\mathrm{PO}_{2}$. Este aspecto tiene un interés primordial para la comprensión de la transducción hipóxica. El primer canal de $\mathrm{K}^{+}$sensible a la $\mathrm{PO}_{2}$, descrito en células quimiorreceptoras de conejo, es dependiente de voltaje y tiene un umbral macroscópico de activación en torno a los $-40 \mathrm{mV}[87,111]$. Dado que el potencial de membrana $\left(\mathrm{E}_{\mathrm{m}}\right)$ de las células oscila entre -50 y $-60 \mathrm{mV}$, el dilema era evidente: si los canales sensibles a $\mathrm{O}_{2}$ estuvieran cerrados, la hipoxia no podría disminuir su Po. La situación era similar en las células quimiorreceptoras de rata, en las que el primer canal sensible a la $\mathrm{PO}_{2}$ descrito era el maxi- $\mathrm{K}^{+}$: en reposo (en normoxia) la concentración intracelular de $\mathrm{Ca}^{2+}$ es baja y el $\mathrm{E}_{\mathrm{m}}$ negativo, por lo que el maxi$\mathrm{K}^{+}$estaría igualmente cerrado y la disminución de la $\mathrm{PO}_{2}$ tampoco podría hacer disminuir la Po. En otras palabras, ninguno de los dos canales con sensibilidad a la hipoxia descritos parecía contri- 
buir, en términos macroscópicos, al mantenimiento del $\mathrm{E}_{\mathrm{m}}$ en reposo (normoxia) y, por tanto, no podían alterarlo. Los argumentos que hemos utilizado $[6,95,112]$ para defender el modelo de membrana son de doble naturaleza: o bien que la Po al $\mathrm{E}_{\mathrm{m}}$ normóxico fuera, aunque muy baja, distinta de cero, o bien que las células presentaran actividad eléctrica espontánea. En ambos casos, la inhibición de los canales de $\mathrm{K}^{+}$por la hipoxia sí que podría regular la cinética de activación de los canales de $\mathrm{Ca}^{2+}$ dependientes de voltaje, $\mathrm{y}$, por tanto, la entrada de $\mathrm{Ca}^{2+}$.

Dos hallazgos recientes parecen resolver esta problemática. El primer hallazgo se realizó en células quimiorreceptoras de rata. En esta especie, varios autores [91,113,114; ver también 115] habían encontrado que el TEA (hasta $20 \mathrm{mM}$ ) y la caribdotoxina (20 nM), separadamente o en combinación con hasta 5 mM de 4aminopiridina, no modificaban en condiciones de normoxia ni el $\mathrm{E}_{\mathrm{m}}$ ni los niveles de $\mathrm{Ca}^{2+}$ de las células quimiorreceptoras aisladas, ni la liberación de DA ni las descargas en el NSC en CC intactos; tampoco afectaban la liberación de DA o la actividad en el NSC evocada por la hipoxia. Las conclusiones de estos estudios eran obvias, como se desprende de los propios títulos de los artículos. Sin embargo, Buckler [91] hizo un hallazgo adicional: las células quimiorreceptoras de rata poseen una corriente leaky, independiente de voltaje, que es inhibida por la hipoxia de forma reversible. Posteriormente identificó al canal que lleva dicha corriente como el TASK-1 [92,93], aunque también podrían contribuir otros canales de la misma familia [116]. Es importante señalar que la sensibilidad a la hipoxia de estos canales leaky, evidente en registros cell-attached, se pierde al escindir los parches de membrana y pasar a registrar en configuración inside-out. En suma, los hallazgos de Buckler han resuelto un problema, pero han arrojado sombras sobre otros aspectos que parecían resueltos, tal como la sensibilidad intrínseca de la membrana celular a la hipoxia (ver más arriba).

El segundo hallazgo se realizó en células quimiorreceptoras de conejo con dominantes negativos para canales de la familia shaker (Kv1) o shal (Kv4) obtenidas por transferencia adenoviral de los correspondientes de genes mutados. En ellas hemos encontrado que sólo las células nulas para la familia Kv4 estaban despolarizadas en condiciones de normoxia y no se despolarizaban ni por la hipoxia ni por las 4-aminopiridinas, lo que indica que estos canales ( $\mathrm{y}$ no los $\mathrm{Kv} 1$ ) contribuyen al mantenimiento del $\mathrm{E}_{\mathrm{m}}$ y son responsables de la despolarización producida por la hipoxia [117]. En experimentos más recientes [118], en los que se ha utilizado una combinación de técnicas electrofisiológicas, microfluorometría con imagen para $\mathrm{Ca}^{2+}, \mathrm{RT}$-PCR, inmunocitoquímica e hibridación in situ, hemos confirmado las observaciones previas al verificar la expresión de subunidades Kv4.1 y Kv4.3 en todas las células quimiorreceptoras, TH-positivas. Además, hemos encontrado que un número importante de células expresa, junto con éstas, subunidades Kv3.4, que también sustentan corrientes transitorias.

En suma, pensamos que el modelo de membrana se ajusta fenomenológicamente a las observaciones experimentales macroscópicas y es capaz de acomodar a un número muy importante de las observaciones existentes en el ámbito celular y molecular.

Mecanismos de transducción de los estímulos ácido e hipercápnico

La anhidrasa carbónica acelera la hidratación y deshidratación del $\mathrm{CO}_{2}$, con lo que hace más rápido el cambio de la concentración de $\mathrm{H}^{+}$en respuesta a alteraciones de la $\mathrm{PCO}_{2}$. Dado que la enzima

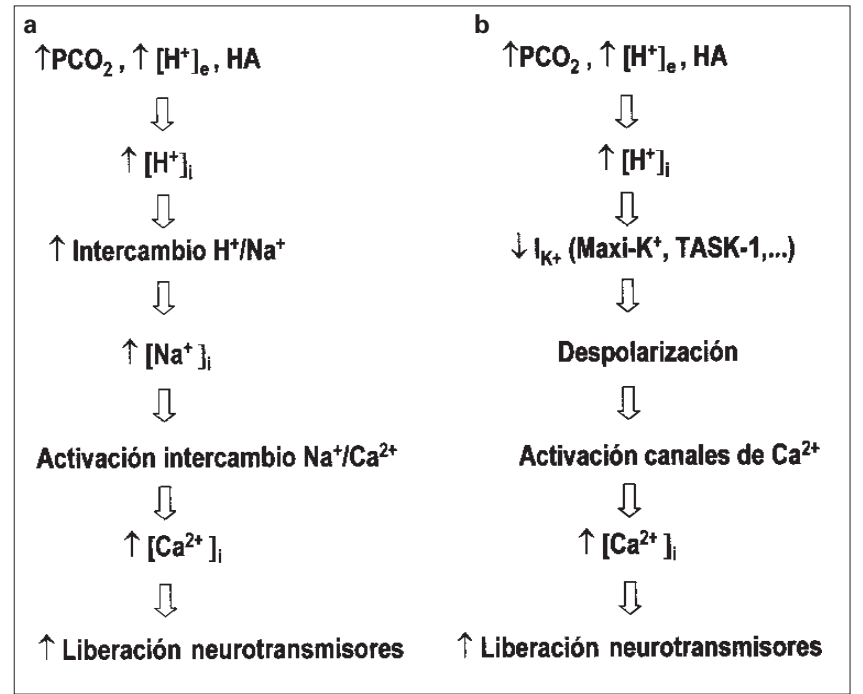

Figura 3. Modelos de transducción del estímulo ácido-hipercápnico. a) Modelo propuesto por nuestro laboratorio (Rocher et al, 1991 [122]). Como puede observarse, la liberación de neurotransmisores en este modelo dependería de la entrada de $\mathrm{Ca}^{2+}$ en intercambio por $\mathrm{Na}^{+}$a través del intercambiador $\mathrm{Na}^{+} / \mathrm{Ca}^{2+}$. b) Modelo propuesto por Buckler et al $[125,126]$, en el que la entrada de $\mathrm{Ca}^{2+}$ tendría lugar por canales de $\mathrm{Ca}^{2+}$ dependientes de voltaje. HA: ácido débil.

se localiza intracelularmente, y que su inhibición elimina los cambios transitorios de la respuesta del CC a la presentación y retirada de un estímulo consistente en un aumento de $\mathrm{CO}_{2}$, podríamos concluir que la señal que se detecta en el CC es la concentración intracelular de $\mathrm{H}^{+}$. Una predicción consistente con esa conclusión es que la perfusión del CC con soluciones a un $\mathrm{pH} 7,40$, pero que contengan ácidos débiles o tengan una $\mathrm{PCO}_{2}$ alta, sería capaz de activar a las células quimiorreceptoras -aumentaría la liberación de DA- y a las terminaciones sensoriales - aumentaría la frecuencia de descargas en el NSC- [119]. Ambas predicciones, relativas al $\mathrm{pH}$ intracelular al inhibir la anhidrasa carbónica y al perfundir con ácidos débiles, han sido verificadas por Buckler et al [120,121] con mediciones directas en células quimiorreceptoras aisladas de rata. En suma: al ser el aumento de la concentración intracelular de $\mathrm{H}^{+}$el estímulo para las células quimiorreceptoras, la pregunta es: ¿cómo es capaz de activar las células un aumento de la concentración intracelular de $\mathrm{H}^{+}$?

En nuestro laboratorio, trabajando en preparación intacta de CC de gato y conejo, encontramos que los estímulos ácidos muy intensos producían una liberación de DA muy pequeña en comparación con los estímulos hipóxicos, aun de intensidad moderada [81,119]. Lo mismo es cierto en CC intacto de rata [76]. Encontramos, por una parte, que la liberación evocada por los estímulos ácidos era dependiente del $\mathrm{Ca}^{2+}$ extracelular en un $80 \%$ (la respuesta hipóxica es dependiente en más de un 95\%) y, por otra, que ni el BayK 8644, una dihidropiridina agonista de canales de $\mathrm{Ca}^{2+}$ dependientes de voltaje tipo L [78], ni la tetrodotoxina [81] modificaban la respuesta secretora inducida por acidosis hipercápnica ni por ácidos débiles. Con estos hallazgos, propusimos que la activación de las células quimiorreceptoras por el ácido no requería despolarización ni participación de canales de $\mathrm{Ca}^{2+}$ dependientes de voltaje como vía de entrada del $\mathrm{Ca}^{2+}$ [122]. Esta propuesta era consistente con que las corrientes de $\mathrm{Ca}^{2+}$ de las células quimiorreceptoras, al igual que las de otra gran variedad de células, se inhiben al disminuir el pH [6,123]. Proponíamos como vía de 
entrada de $\mathrm{Ca}^{2+}$ el funcionamiento en modo reverso del intercambiador $\mathrm{Na}^{+} / \mathrm{Ca}^{2+}$ que estaría movido por el aumento de $\mathrm{Na}^{+}$intracelular producido por los mecanismos de expulsión de $\mathrm{H}^{+}$de las células quimiorreceptoras (intercambiadores $\mathrm{Na}^{+} / \mathrm{H}^{+}$y $\mathrm{Na}^{+}, \mathrm{HCO}_{3}{ }^{-} / \mathrm{H}^{+}, \mathrm{Cl}^{-}$), de cuya existencia se obtuvo evidencia experimental en $\mathrm{CC}$ de conejo intacto [79,122]. Propusimos el siguiente modelo: el aumento de la concentración intracelular de $\mathrm{H}^{+}$activa los mecanismos homeostáticos de las células, que expulsan $\mathrm{H}^{+}$en intercambio por $\mathrm{Na}^{+}$con el consiguiente aumento de la concentración intracelular de $\mathrm{Na}^{+}$. Este aumento activaría el intercambio de $\mathrm{Na}^{+} / \mathrm{Ca}^{2+}$, con salida de $\mathrm{Na}^{+}$e ingreso de $\mathrm{Ca}^{2+}$, que promovería la respuesta secretora $[6,95,122]$. La expulsión de $\mathrm{Na}^{+}$de las células en intercambio con $\mathrm{Ca}^{2+}$ se vería favorecida porque la acidificación intracelular inhibe la bomba de $\mathrm{Na}^{+}$[124] (Fig. 3a).

Buckler y Vaughan-Jones [125,126] han obtenido en células quimiorreceptoras aisladas de rata datos que entran en conflicto frontal con la descripción que acabamos de hacer. Estos autores encuentran que los estímulos ácidos despolarizan las células y generan potenciales de acción, que deben ser potenciales de $\mathrm{Ca}^{2+}$, porque las células quimiorreceptoras de rata no poseen canales de $\mathrm{Na}^{+}$(Fig. 3b). La amplitud de la despolarización y de las ráfagas de potenciales de acción, así como los aumentos de la concentración intracelular de $\mathrm{Ca}^{2+}$ producidos por los estímulos ácidos en las células quimiorreceptoras son comparables a las producidas por la hipoxia [comparar 126 y 127], lo que contrasta con la escasa capacidad de los estímulos ácidos para liberar DA tanto en rata [76] como en gato [comparar 75 y 119] como en conejo [78] o para aumentar la frecuencia de descargas en el NSC [128]. Podría argumentarse que la acidificación intracelular reduciría la afinidad de la maquinaria exocitótica por el $\mathrm{Ca}^{2+}$, con lo que, a pesar del aumento relativamente alto de la concentración intracelular de $\mathrm{Ca}^{2+}$ la respuesta secretora sea pequeña. Sin embargo, esta posibilidad contradice la potenciación de respuestas que se observa entre los estímulos hipóxicos y ácidos [129]. Finalmente, aunque la gran sensibilidad del maxi-K a la acidificación intracelular [130] es congruente con la despolarización que producen los estímulos ácidos en las células quimiorreceptoras, el TASK-1 es sensible al pH extracelular [93] y, según hemos comentado, los ácidos débiles, incluido el propio $\mathrm{CO}_{2}$, producen un aumento del $\mathrm{Ca}^{2+}$ intracelular aun con un pH extracelular de 7,40 [125,126]. En suma, también en el caso de la transducción del estímulo ácido existen inconsistencias, algunas tal vez debidas a diferencias entre especies, que requieren experimentos adicionales para su clarificación. Por ejemplo, mientras que nuestros experimentos pusieron de manifiesto la presencia de un intercambiador $\mathrm{Na}^{+} / \mathrm{Ca}^{2+}$ muy potente en células quimiorreceptoras de conejo-ya que la inhibición de la bomba de $\mathrm{Na}^{+} / \mathrm{K}^{+}$(oubaína y eliminación de $\mathrm{K}^{+}$del medio extracelular) promueve una respuesta secretora intensa que desaparece cuando no hay $\mathrm{Na}^{+}$y $\mathrm{Ca}^{2+}$ extracelular [122]-, Buckler y Vaughan Jones encontraban que dicho intercambiador jugaba un papel menor en la homeostasis del $\mathrm{Ca}^{2+}$ en las células quimiorreceptoras de rata [126].

\section{Neurotransmisión entre las células quimiorreceptoras y las terminaciones sensoriales del nervio del seno carotídeo Aspectos históricos}

La idea de un proceso de neurotransmisión entre las células quimiorreceptoras y las terminaciones sensoriales está presente en la misma definición del CC como un órgano sensorial [11]. Hasta finales de 1950, el único neurotransmisor considerado en el CC era la ACh, cuya naturaleza quimioexcitatoria había sido descubierta por Heymans et al y por Anichkov et al en 1936 [ver 52].
En 1938 Schweitzer y Wright [131] observaron que la fisostigmina (un anticolinesterásico) activaba la ventilación, al igual que la ACh, y concluían que la ACh sería el neurotransmisor en el CC. Hasta 1968 ha habido múltiples estudios [52,132-135]. El principal contencioso en todos estos años era que los bloqueadores nicotínicos (el efecto estimulante de la ACh es nicotínico), aunque eliminaban el efecto estimulatorio de la ACh exógena, sólo reducían parcialmente la respuesta a la hipoxia.

En el año 1957, Lever and Boyd [136], en uno de los primeros estudios del CC al microscopio electrónico, demostraron la presencia en las células quimiorreceptoras de gránulos de núcleo denso, comparables a los de las células cromafines de la médula adrenal, y proponían que tal vez se debiera a que las CA fueran los neurotransmisores. Esta propuesta promovió múltiples estudios para demostrar a nivel bioquímico e histoquímico la presencia de CA en el CC de todas las especies y en los que se estudió a nivel farmacológico el efecto de las CA sobre la actividad eléctrica en el NSC o sobre la ventilación [ver revisión en 65]). La problemática con las CA como posibles neurotransmisores en la unión célula glómica-terminaciones sensoriales del NSC es que las CA exógenas no siempre mimetizan los efectos de los estímulos naturales: en vez de estimular, como la hipoxia, con frecuencia inhiben las descargas en el NSC o la ventilación.

Además de la presencia de serotonina en el CC, demostrada por Chiochio et al. en 1967 [137], y cuyo significado funcional es dudoso [25], existen evidencias bioquímicas e inmunocitoquímicas de la existencia de un número importante de neuropéptidos (ver el apartado Organización estructural). Aunque existen observaciones experimentales respecto a acciones concretas de uno u otro péptido, el significado funcional general de los neuropéptidos en el CC, ya sea como moduladores de la función de las células glómicas o de la transmisión sináptica, o como factores tróficos a largo plazo, no está bien definida $[23,25]$. Cabe destacar a la sustancia $\mathrm{P}$ por la gran atención que ha recibido. La ausencia de ARNm que codifique para este neuropéptido en las células quimiorreceptoras la excluye como neurotransmisor primario, pero muy bien pudiera ser que la liberación de sustancia P de las terminaciones sensoriales, donde es muy abundante ([27]; función eferente de las terminaciones aferentes), fuera capaz de modular la actividad quimiorreceptora. Sin embargo, a la hora de asignar un papel a la sustancia $\mathrm{P}$, los datos farmacológicos son conflictivos (comparar [138] con $[139,140])$; además, la observación en knock outs para receptores NK-1 de que la actividad basal y la respuesta a la hipoxia en el NSC es idéntica a la observada en los animales controles [26] cuestiona seriamente un papel significativo para este neuropéptido en la quimiorrecepción arterial. Los péptidos opioides, presentes en las células quimorreceptoras, son inhibidores tanto de la actividad en el NSC como de la ventilación [6,141], y al menos parte de sus acciones las ejercen mediante receptores presinápticos, ya que son capaces de inhibir la respuesta secretora de las células quimiorreceptoras frente a gran variedad de estímulos [142].

Una última consideración que hacer en esta introducción histórica hace referencia a la aparición de la preparación del CC in vitro. Dado que muchas de las sustancias propuestas como transmisores (y sus agonistas y antagonistas) en el CC son vasoactivas, la interpretación de los experimentos con CC in situ se complica por el hecho de que la modificación del flujo sanguíneo altera por sí misma la descarga quimiorreceptora, por lo que no se sabe si el efecto observado ante la aplicación de una droga se genera a nivel vascular o a nivel de la sinapsis entre células quimiorreceptoras y terminaciones sensoriales. Para obviar estas incertidumbres, 
Tabla. Criterios de McLennan a para asignar a una sustancia el papel de neurotransmisor y su grado de cumplimiento por distintos candidatos a neurotransmisores, neuromoduladores o cotransmisores.

\begin{tabular}{|c|c|c|c|c|}
\hline & Acetilcolina & Dopamina & Sustancia P & ATP \\
\hline Presencia en el elemento presináptico en concentración adecuada & \pm & + & \pm & + \\
\hline $\begin{array}{l}\text { Presencia de maquinaria responsable de su síntesis o almacenamiento } \\
\text { en el elemento presináptico. La inhibición de estos sistemas } \\
\text { debe alterar la neurotransmisión de forma predecible }\end{array}$ & \pm & + & - & + \\
\hline Liberación del elemento presináptico en relación con la intensidad de la estimulación & \pm & + & \pm & $?$ \\
\hline Presencia de receptores en el elemento postsináptico & + & + & $?$ & + \\
\hline $\begin{array}{l}\text { Presencia de mecanismos de inactivación (sistema enzimático, captación o recaptación y lavado). } \\
\text { La inhibición de estos sistemas debe alterar la neurotransmisión de forma predecible }\end{array}$ & + & + & + & + \\
\hline $\begin{array}{l}\text { Identidad de acción: la sustancia candidata a neurotransmisor debe mimetizar } \\
\text { los efectos de la estimulación natural }\end{array}$ & + & \pm & \pm & \pm \\
\hline Bloqueo: el bloqueo de los receptores postsinápticos debe abolir el efecto de la estimulación natural & + & \pm & \pm & \pm \\
\hline
\end{tabular}

El signo ' + ', indica consenso en la literatura sobre la demostración satisfactoria del criterio; ' \pm ', la existencia de datos contradictorios en la literatura; '-', que la literatura disponible no satisface el cumplimiento de ese criterio; ' ?', indica que ese aspecto particular no ha sido estudiado. ${ }^{a}$ La formulación de los criterios de McLennan en esta tabla no sigue ni el enunciado ni el orden de la formulación originales expuestos por el autor en su libro [144]. No obstante, utilizamos el nombre de McLennan por su valor histórico, ya que la propuesta de McLennan constituye, tal vez, la primera en la que se presentan de forma sistematizada tanto criterios fisiológicos como farmacológicos.

Eyzaguirre y Lewin [143] desarrollaron una preparación de CC superfundido in vitro en la que se evitan los efectos vasculares. Así se facilita la interpretación de los hallazgos; además esta preparación, o variantes de la misma, han permitido profundizar en el análisis de múltiples aspectos neuroquímicos y metabólicos del CC.

\section{Hipótesis colinérgica}

Aunque no sea en párrafos diferenciados, vamos a seguir los criterios clásicos de McLennan [144] en la discusión de las hipótesis de la neurotransmisión entre las células quimiorreceptoras y las terminaciones sensoriales del NSC (Tabla). Así pues, hemos de preguntarnos: ¿existe ACh en las células glómicas para que pueda ser el neurotransmisor entre las células y las terminaciones nerviosas? ¿Existen los sistemas enzimáticos para sintetizarla y los transportadores para almacenarla? Según hemos comentado, existen discrepancias entre contenido y síntesis de ACh en el CC: Fidone et al. [30] y Hellstrom [31] encontraron niveles similares (por unidad de peso) en CC de rata y gato, mientras que en nuestro laboratorio hemos observado que el CC de gato no sintetiza ACh ni tiene actividad ChAT [32]. Wang et al. [145] encuentran mediante inmunocitoquímica ChAT en células quimiorreceptoras de gato y conejo, y más recientemente Nurse y Zhang [146] encuentran el transportador de ACh en células quimiorreceptoras en cultivo obtenidas de ratas jóvenes. El peso de la evidencia parece indicar que las células glómicas serían colinérgicas [147] y contradicen la evidencia negativa de los experimentos de Almaraz [32]. Sin embargo, Gauda [29] encuentra que las células quimiorreceptoras no poseen mensajero para la ChAT ni para el transportador de ACh y critica la especificidad de los anticuerpos utilizados por Wang et al [145] y propone la inducción de rasgos colinérgicos (como el transportador de ACh) en las células quimiorreceptoras en cultivo [ver 148]. A pesar de estos hallazgos, la duda persiste: ¿dónde está localizada la ACh que se ha detectado en el CC? Schütz et al [149] encontraron que el transportador para $\mathrm{ACh}$ se localizaba en algunas terminaciones nerviosas en el CC y en la neuronas localizadas en la periferia del CC, y no en las células quimiorreceptoras; Gauda [29] encuentra lo mismo: alguna neurona periglómica y algunas neuronas del petroso son positivas para ChAT. Estas neuronas podrían contener la $\mathrm{ACh}$, pero un recambio bajo de la misma en estas estructuras podría explicar la ausencia de síntesis de ACh. Sin embargo, cinética y autorradiográficamente se ha demostrado la presencia de un sistema de captación de colina de alta afinidad en las células quimiorreceptoras [150,151]. Dado que este sistema de captación es un marcador colinérgico, las células quimiorreceptoras habrían de ser colinérgicas.

La existencia de acetilcolinesterasa, como mecanismo de inactivación de ACh, se ha demostrado en multitud de estudios, aunque no sabemos nada de las posibles isoformas de la enzima localizadas en el CC $[65,147]$. La liberación de ACh del CC en respuesta a la estimulación natural ha sido demostrada por Eyzaguirre y sus colaboradores en los años 60, en experimentos tipo Loewi [152,153]. Más recientemente, Fitzgerald et al [154-156] han confirmado con HPLC la presencia de ACh en efluentes del CC y un aumento de la misma al perfundir con soluciones hipóxicas; sorprendentemente, en ninguno de estos estudios se han proporcionado datos del contenido de ACh en el CC.

La existencia de receptores nicotínicos en el CC era evidente, ya que multitud de agentes nicotínicos estimulaban los quimiorreceptores. Sin embargo, la pregunta era dónde estaban localizados Demostramos una unión (binding) específica de $\alpha$-bungarotoxina en el CC, que localizamos autorradiográficamente en las células quimiorreceptoras y que no se modificaba tras la denervación del NSC $[157,158]$. Esto nos llevó a proponer que los agentes nicotínicos producirían sus efectos a nivel presináptico. Observaciones posteriores, al comparar las acciones de la $\alpha$-bungarotoxina con las de la mecamilamina, nos llevaron a sugerir la existencia de un subgrupo de receptores nicotínicos no marcados por la toxina y que, por tanto, podrían encontrarse en las terminaciones nerviosas sensoriales [159]. Shirahata et al [160] y, más recientemente, Gauda [29] han demostrado por inmunocitoquímica y por hibridación in situ la presencia de dichos receptores en células quimiorreceptores y en terminaciones sensoriales, asícomo la presencia de ARNm para dichas subunidades en neuronas del ganglio petroso. Las células quimiorreceptoras también expresan receptores muscarínicos que son de naturaleza fundamentalmente inhibitoria [161-163].

De los dos criterios farmacólogicos -el de identidad de acción 


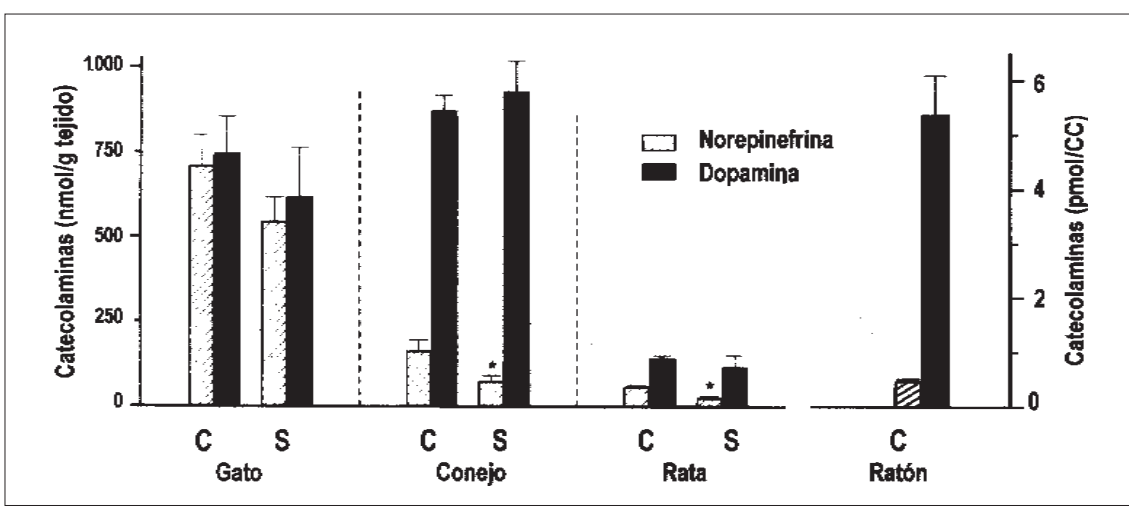

Figura 4. Contenido de catecolaminas en el cuerpo carotídeo de distintas especies. C: cuerpos carotídeos control; S: cuerpos carotídeos provenientes de animales en los que el ganglio cervical superior ha sido extirpado quirúrgicamente 7-15 días antes de la extirpación de los cuerpos carotídeos para análisis. Para gato, conejo y rata, los contenidos se expresan por unidad de peso de tejido; para ratón, se expresan por cuerpo carotídeo (CC).

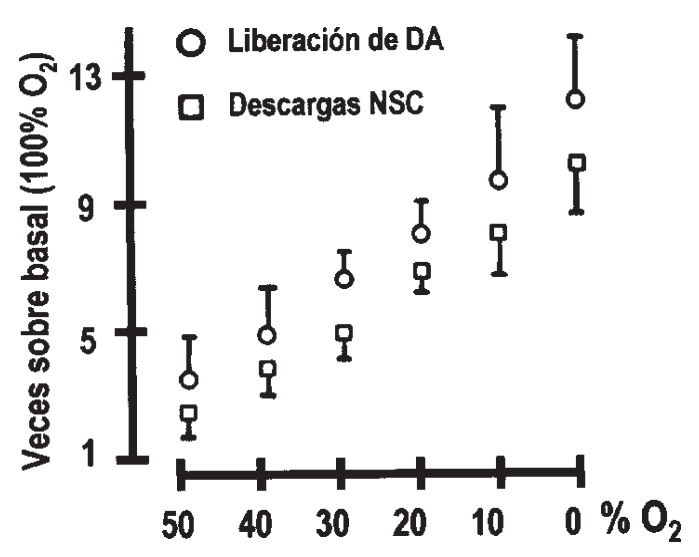

Figura 5. Liberación de dopamina (DA) por el cuerpo carotídeo y actividad eléctrica en el nervio del seno carotídeo (NSC) en conejo superfundido con soluciones saturadas con mezclas de gases que contenían el porcentaje de $\mathrm{O}_{2}$ que aparece en abscisas. La liberación basal se obtuvo durante periodos de idéntica duración de superfusión con soluciones equilibradas con $100 \%$ de $\mathrm{O}_{2}$.

y el de bloqueo- el primero ha sido claramente demostrado por multitud de investigadores y es el origen de la propia hipótesis colinérgica: todos los agentes nicotínicos originan reflejos en el CC que aumentan la ventilación y aumentan las descargas en el NSC; los agonistas nicotínicos aumentan la liberación de DA en las células quimorreceptoras, despolarizan las células, producen una corriente de entrada y aumentan la concentración intracelular de $\mathrm{Ca}^{2+}[7,147]$. El criterio del bloqueo de la estimulación natural por los bloqueadores nicotínicos ha sido la bandera de los críticos de la hipótesis colinérgica: dichos agentes eliminaban completamente la activación producida por los agonistas nicotínicos, pero sólo parcialmente la activación producida por la estimulación natural. Sin embargo, este bloqueo incompleto [164] hay que verlo en la actualidad bajo la perspectiva de la cotransmisión, y no desde la concepción errónea del principio de Dale [165]. En este sentido, Nurse et al $[48,146,166,167]$ encuentran que las células quimiorreceptoras y las neuronas del petroso en cocultivo forman sinapsis funcionales, de tal forma que, registrando en las neuronas tras formar las sinapsis, y no antes, es posible observar actividad espontánea y un aumento de descargas en respuesta a la hipoxia que se bloquean por una mezcla de bloquedores nicotínicos (mecamilamina) y purinérgicos (suramina), por lo que concluyen que la transmisión en la sinapsis célula quimiorreceptora-terminación sensorial, al menos en el medio artificial que supone el cultivo, es una cotransmisión nicotínica y purinérgica. Los receptores purinérgicos responsables de la cotranmisión en el CC serían receptores $\mathrm{P} 2 \mathrm{X} 2$ y $\mathrm{P} 2 \mathrm{X} 3$ (ya sea como homorreceptores o como heterorreceptores), cuya expresión se solapa muy frecuentemente en las mismas neuronas del ganglio petroso y en las terminaciones nerviosas del NSC a nivel intraglómico [168].

En suma, ha habido varios ciclos vitales en la hipótesis colinérgica. Un primer ciclo, de ascensión, va desde su nacimiento en los años 30 del siglo pasado hasta la revisión de Eyzaguirre y Zapata en 1968 [135], en la que la hipótesis se consolidó como doctrina de los mecanismos de quimiorrecepción. Las ideas de Biscoe [35] de que el CC era un receptor sensorial primario y otras críticas derivadas de la incapacidad de los bloqueadores nicotínicos para eliminar la respuesta a la hipoxia y los datos de unión con $\alpha$-bungarotoxina llevaron a la hipótesis a su punto más bajo. Los datos de inmunocitoquímica de ChAT y del receptor nicótínico y los datos de cotransmisión en cultivos han vuelto a elevar la hipótesis colinérgica, pero las observaciones de Gauda [29], de ausencia de ChAT en células glómicas, parecen cuestionar una vez más dicha hipótesis.

\section{Hipótesis catecolaminérgica o dopaminérgica}

La presencia de CA en el CC, incluido el humano, se ha demostrado en muchos laboratorios [ver referencias en 6,25,65]. El contenido de DA es alto en todas las especies, pero las proporciones DA/NA varían (Fig. 4): hay animales cuyos CC son principalmente dopaminérgicos (conejo, rata y ratón) y otros mixtos, dopaminérgicos y noradrenérgicos (gato). Aunque los valores absolutos de CA referidos al CC humano tienen poco valor, ya que los órganos son obtenidos en necropsias a distintos tiempos post mortem, parece que el CC humano es, preferentemente, dopaminérgico [169,170].

Las enzimas involucradas en la síntesis de CA, y el propio proceso de síntesis, han sido estudiado por varios laboratorios y, de forma muy extensa, por González et al [69-72,75,171]; los mecanismos de inactivación fueron igualmente estudiados en nuestro laboratorio [172]. De estos estudios destacamos que la tirosina hidroxilasa se induce por hipoxia en rata, conejo y gato (la hipoxia aumentó la Vmax sin cambiar la $\mathrm{Km}$ ), aspecto, este último, verificado posteriormente a nivel de ARNm [173]. Las células glómicas carecen de un sistema de captación de CA de alta afinidad, pero poseen un sistema de baja afinidad y fuerte actividad monoamino oxidasa y catecol-O-metiltransferasa, a juzgar por los catabolitos de la DA que se producen en el CC. La falta del sistema de alta afinidad explicaría la insensibilidad del CC a la 6hidroxidopamina [174].

En experimentos de unión demostramos la existencia de receptores DA-2, cuya densidad se reducía en torno al $50 \%$ al seccionar crónicamente el NSC: esto indica que la mitad de los receptores DA-2 serían autorreceptores en las células glómicas, y la otra mitad, receptores postsinápticos [175]. Posteriormente, obtuvimos evidencias de la presencia de receptores de la familia 
DA-1 en el CC, ya que la DA y los agonistas dopaminérgicos DA1 aumentaban los niveles de AMPc y los antagonistas específicos revertían el efecto [176]. Estas observaciones han sido confirmadas por hibridación in situ, Northern blot y RT-PCR por varios laboratorios [29,177-180].

La liberación de DA y NA ha sido sugerida por múltiples estudios in vivo al demostrar una disminución de DA o NA asociada a un aumento del recambio de las mismas tras un episodio agudo de hipoxia [e.g. 181]. Sin embargo, han sido los laboratorios de Fidone y el nuestro propio los que han caracterizado más en detalle, utilizando métodos radiosotópicos, la liberación de CA en relación con multitud de estímulos [58,68,74-77,81,119, 122,182-186], en especial para el estímulo hipóxico(Fig. 5). Varios laboratorios han estudiado la liberación de DA, también en órgano intacto, pero con técnicas voltamétricas [26,187-190]. En células aisladas, nosotros caracterizamos la liberación de DA inducida por la hipoxia, incluida su dependencia de $\mathrm{Ca}^{2+}$, por métodos radioisotópicos [85]; posteriormente, otros laboratorios han confirmado y refinado nuestras observaciones con métodos voltamétricos [e.g. 191,192]). La liberación de CA en el CC intacto o células quimiorreceptoras aisladas trasciende a la neurotransmisión sensu stricto, ya que es un parámetro que se utiliza como índice de la activación de las células quimiorreceptoras: no existe, que sepamos, ningún estímulo para el CC que no aumente la liberación de CA y, además, existe una correlación razonable entre intensidad de estimulación y aumento de liberación de DA y de frecuencia de potenciales de acción en el NSC frente a múltiples estímulos [25,95]. A este respecto, existen estudios de Donnelly [193,194] e Iturriaga et al [189] en los que se muestra que, frente a estimulación repetida o en animales reserpinizados, tal paralelismo se rompe: la liberación de DA disminuye con cada nuevo estímulo, pero la frecuencia de descargas en el NSC se mantiene esencialmente constante. Hay que destacar que este es el patrón normal de conducta de los sistemas catecolaminérgicos a la estimulación repetida y a la reserpinización [195-198].

Los criterios fisiológicos (presencia, maquinaria de biosíntesis, liberación, presencia de receptores e inactivación) que acabamos de describir para la DA se cumplen satisfactoriamente para considerar a esta CA como el neurotransmisor excitador primario, pero también para considerar a la DA como un cotransmisor o neuromodulador, ya sea excitatorio o inhibitorio. Son, por tanto, los criterios farmacológicos -criterios de identidad de acción y de bloqueo- los que han de constituir la base para asignar a la DA un significado funcional u otro. Sin embargo, la interpretación de los hallazgos encaminados a verificar esos dos criterios no es unívoca: aun cuando los hallazgos experimentales son incontrovertibles (reservado el margen del error experimental), existen muchos argumentos e incertidumbres que permiten asignar a esos hallazgos un significado funcional o el opuesto, según prejuicios personales que, consideramos, son científicamente aceptables. Así por ejemplo, la DA inyectada intracarotídeamente va a poder actuar [6,141] al menos sobre:

- Posibles receptores dopaminérgicos localizados en los vasos intraglómicos; al alterar el flujo sanguíneo puede modificar la actividad eléctrica en el NSC, tanto en condiciones de normoxia como de hipoxia [176].

- Receptores presinápticos en las células quimiorreceptoras (autorreceptores), cuya activación va a producir inhibición de la liberación endógena de DA [199].

- Receptores postsinápticos localizados en las terminaciones sensoriales del NSC, donde generará una respuesta que no se sabe cuál es, ya sea aumento o disminución de la actividad en el NSC; hay que señalar, sin embargo, que en ganglio petroso aislado y con todas sus ramas seccionadas, la DA inhibe la actividad evocada por la aplicación de ACh y registrada antidrómicamente en el NSC, sin afectar la actividad espontánea que muestran las neuronas del ganglio petroso [200].

A esta multiplicidad de sitios de acción de la DA hay que añadir incertidumbres interpretativas derivadas de estudios realizados con dosis únicas o curvas dosis-respuesta incompletas, tal como señala McQueen [201] en su amplia revisión.

Trataremos de forma más detallada los datos obtenidos en gato, ya que ha sido la especie más utilizada en el estudio de los criterios farmacológicos de la DA. Teniendo en cuenta las consideraciones hechas en el párrafo anterior, la observación experimental más común de que la DA a dosis bajas, ya sea inyectada intracarotídea o intravenosamente in vivo, o aplicada a la preparación superfundida in vitro, produce inhibición de las descargas [202-208] puede ser interpretada legítimamente suponiendo que la DA es un neurotransmisor o neuromodulador inhibitorio $[141,209]$. Sin embargo, puede argumentarse que en los experimentos in vivo la DA inyectada produciría vasodilatación y, por tanto, un aumento de flujo al CC y una disminución de la descarga por aumento del aporte de $\mathrm{O}_{2}$ (no se sabe si los vasos intraglómicos poseen receptores dopaminérgicos en esta especie animal); en todos los experimentos, tanto in vivo como in vitro, la DA exógena produciría, además, inhibición de la liberación endógena de DA actuando sobre autorreceptores, con el resultado neto de una disminución real de la concentración de DA a nivel del espacio sináptico. La sugerencia de actuación preferencial sobre los autorreceptores antes que sobre los receptores postsinápticos se basa en observaciones hechas en otros sistemas. Así, Siggins [210], discutiendo sobre la afinidad o sensibilidad de los receptores extrasinápticos, presinápticos y postsinápticos escribía: 'Therefore, it is reasonable to expect that the «lowest dose» response of neurons to bath-applied transmitters might reflect more a presynaptic mechanism than the response to higher transmitter concentrations' [ver también 211]. Estas consideraciones pueden llevar a concluir, también legítimamente, que la DA es un neurotransmisor o un neuromodulador excitatorio capaz de aumentar la actividad del NSC actuando sobre los receptores postsinápticos [6,25].

Siguiendo con el CC de gato, la DA administrada a concentraciones altas, tanto in vivo como in vitro, y a todas las concentraciones tras la administración de bloqueadores dopaminérgicos, es preferentemente excitadora, y hace aumentar la frecuencia de descargas en el NSC [202-205,212]. Además, también es común observar que la administración de antagonistas dopaminérgicos per se (espiroperidol, haloperidol, droperidol, metoclopramida, sulpiride, domperidona) aumenta la frecuencia basal de descargas en NSC y el nivel de la ventilación en reposo [205,213-218]; la respuesta del CC a la estimulación hipóxica también está aumentada tras la aplicación de bloqueadores dopaminérgicos [213,215,219]. Independientemente de cualquier prejuicio, lo que estos hallazgos dicen es que hay receptores dopaminérgicos en el CC que son capaces de estimular la actividad quimiorreceptora, y que estos receptores (opuestamente a los que producen inhibición de la actividad quimiorreceptora) deben poseer una menor afinidad o accesibilidad para la DA, ya que se requieren dosis altas de DA para activarlos; también deben poseer menor afinidad o accesibilidad para los antagonistas dopaminérgicos, ya que resisten su bloqueo a las concentraciones que eliminan los efectos inhibitorios de la DA. La 
pregunta que consideramos que debemos formularnos es cómo ocurren las cosas fisiológicamente, sobre qué receptores está actuando la DA endógena que sabemos que se libera de forma basal y cuya liberación aumenta durante la hipoxia.

Con el conjunto de hechos aportados en esta sección contestaríamos a esa pregunta así: en condiciones basales, la DA liberada está contribuyendo a generar el nivel de actividad en el NSC actuando sobre receptores postsinápticos; dada la baja velocidad de liberación de DA, su concentración a nivel de los receptores presinápticos sería baja, pero suficiente como para ejercer una inhibición tónica de la liberación basal de DA, merced a la gran afinidad de estos receptores por la DA [199]. El bloqueo de los receptores dopaminérgicos presinápticos aumenta la liberación de DA lo que explicaría que los antagonistas dopaminérgicos activaran las descargas en el NSC, ya que producirían un aumento de la concentración de DA en el espacio sináptico, al nivel de los receptores postsinápticos. La inhibición preferencial de los receptores presinápticos sobre los postsinápticos ha sido descrita en otras estructuras [220,221]. Sin embargo, los antagonistas dopaminérgicos a dosis altas son capaces de abolir la actividad basal en el NSC [222] y de abolir las respuestas del CC a la asfixia [214], ya que, aunque provoquen un aumento de la liberación de DA, los antagonistas alcanzarían concentraciones adecuadas en el espacio sináptico y los receptores postsinápticos como para bloquear la acción de la DA endógena sobre estos receptores. Según hemos argumentado antes, la administración exógena de DA o de agonistas dopaminérgicos a dosis bajas actuaría preferentemente sobre los receptores vasculares y presinápticos, haciendo aumentar el flujo sanguíneo al CC e inhibiendo la liberación de DA endógena, con la consiguiente disminución de la concentración de DA a nivel de los receptores postsinápticos y con el resultado neto de inhibición; este efecto sería cierto en condiciones basales y durante la estimulación hipóxica o hipercápnica, aunque en condiciones de estimulación el efecto relativo debería ser menor. La administración de dosis altas de DA o de sus agonistas produciría directamente aumento de las descargas, ya que, independientemente de lo que ocurra con la liberación de la DA endógena, la DA aplicada exógenamente alcanzaría concentraciones adecuadas a nivel de los receptores postsinápticos como para producir el efecto estimulatorio. El lector atento apreciará que esta interpretación, que implica que la DA es considerada como un transmisor, un modulador o un cotransmisor excitatorio, se basa en observaciones que son incompletas y requiere hechos experimentales adicionales para su verificación.

Lasituación en otras especies es cualitativamente similar [6,141], por lo que la interpretación dada en el párrafo anterior sería aplicable a todas las especies. Las posibles diferencias cuantitativas observadas deberían atribuirse a diversas proporciones de receptores dopaminérgicos vasculares y presinápticos y postsinápticos [6]. Únicamente deseamos referirnos a un trabajo reciente realizado en cocultivos de células quimiorreceptoras y neuronas del ganglio petroso de rata, en el que Zhong et al [48] encuentran que la espiperona (5-50 $\mathrm{mM}$ ) no previno o tuvo un efecto 'no apreciable' sobre el aumento de descargas evocado por la hipoxia en las cinco neuronas registradas, mientras que la respuesta fue inhibida reversiblemente por hexametonio 100-200 mM. Sin embargo, esta observación/conclusión requiere, al menos, tres consideraciones:

a) En los registros tipo que se muestran para la respuesta hipóxica control y en presencia de $20 \mathrm{mM}$ de espiperona obtenidos de la misma célula, la respuesta a la hipoxia es un $33 \%$ menor en presencia de la droga (no se proporcionan más datos en el artículo). b) La espiperona, al actuar sobre los autorreceptores de las células quimiorreceptoras, va a aumentar la liberación de DA, por lo que la concentración de DA en la unión sináptica debería ser mayor en presencia que en ausencia del bloqueador dopaminérgico.

c) Por el contrario, el hexametonio debe estar bloqueando la acción de la ACh tanto postináptica como presinápticamente; esto es, en presencia de hexametonio, la concentración de DA en el espacio sináptico debe ser menor que en condiciones control, ya que, si la activación de los receptores nicotínicos aumenta el $\mathrm{Ca}^{2+}$ intracelular y la liberación de $\mathrm{CA}$, su bloqueo debería disminuirla [159].

\section{Otros neurotransmisores}

Ya hemos mencionado en la sección de estructura que en el CC existe un gran número de sustancias que en otros sistemas juegan un papel de cotransmisores o de moduladores de la actividad sináptica. Cabe señalar en este sentido al ATP. En párrafos anteriores, al hablar de la teoría colinérgica, nos hemos referido a hallazgos recientes obtenidos por el grupo de Nurse en cocultivos de células quimiorreceptoras y neuronas del ganglio petroso de rata, los cuales indican que el ATP desempeña un papel importante en la comunicación entre estas dos estructuras en las condiciones del cocultivo. Sin embargo, los trabajos de farmacología clásica [223-225] no apoyan unánimemente estos hallazgos. Los primeros autores $[223,224]$ encuentran que mientras que el ATP y la adenosina aumentan la actividad en el NSC del gato, con curvas dosis-respuesta superponibles, los análogos no hidrolizables de ATP la disminuyen, por lo que concluyen que la estimulación producida por el ATP estaría mediada por la adenosina liberada tras la hidrólisis del nucleótido. Por su parte, Spergel y Lahiri [225] encuentran que la infusión sostenida de ATP induce una activación de las descargas en el NSC, seguida por una desensibilización y desaparición de la respuesta, mientras que la misma maniobra no afectó a la respuesta inducida por la hipoxia: si el ATP fuera un mediador importante de la respuesta hipóxica, ésta debería ser atenuada por la infusión previa de ATP.

La adenosina actuando vía receptores $\mathrm{A}_{2 \mathrm{~A}}$ [ver 29], es capaz de activar la ventilación y de aumentar la actividad eléctrica en el NSC, por lo que habitualmente se considera un modulador excitatorio [223,224,226,227]; sin embargo, existe evidencia neuroquímica y electrofisiológica de que las células quimiorreceptoras poseen receptores $\mathrm{A}_{1}$ de carácter inhibitorio, ya que inhiben las corrientes de $\mathrm{Ca}^{2+}$ y la liberación de DA inducida por la hipoxia [228], por lo que la acción global de la adenosina, que es excitatoria, debe representar un balance entre las acciones mediadas por los dos subtipos de receptores.

Por último, las funciones de los neuropéptidos tampoco están definidas. La sustancia $\mathrm{P}$, que inyectada exógenamente activa la ventilación y aumenta la frecuencia de potenciales de acción en el NSC en la mayoría de las especies estudiadas [26], no parece satisfacer el criterio mínimo de presencia/biosíntesis en el elemento presináptico. Parece que la sustancia $P$ podría ser liberada de las terminaciones nerviosas y ser captada por las células quimiorreceptoras en algunas especies, tal vez por endocitosis, de modo que actuaría como un falso neurotransmisor modulando la comunicación entre las células quimiorreceptoras y las terminaciones sensoriales. Sin embargo, esta modulación no se hace patente en respuesta a la estimulación aguda, ya que la eliminación por manipulación genética de los receptores NK-1, que median los efectos de la sustancia $\mathrm{P}$ exógena, no afectan a la respuesta aguda a la hipoxia. 
Sobre los péptidos opioides parece que hay consenso en que son moduladores inhibitorios [141]. Existen otras sustancias que se sabe que modulan la actividad en el NSC o la ventilación mediada por el CC; sin embargo en la generalidad de los casos, la información disponible es fragmentaria y no permite sacar conclusiones sobre su significado funcional [ver referencias en 141].

\section{Conclusiones sobre la neurotransmisión en el CC}

La comunicación entre células quimiorreceptoras y las terminaciones sensoriales del NSC es compleja y no está suficientemente esclarecida. La literatura más reciente parece indicar que el ATP y los receptores purinérgicos $\mathrm{P} 2 \mathrm{X} 2$ y $\mathrm{P} 2 \mathrm{X} 3$ desempeñan un papel clave en la transmisión de información en esta sinapsis sensorial, tal y como se establece en condiciones de cocultivo entre células quimiorreceptoras y neuronas del ganglio petroso de la rata. Sin embargo, para aceptar tal papel pensamos que es necesario confirmar los resultados en preparaciones intactas in vitro con objeto de eliminar dudas sobre posibles alteraciones en la expresión de genes en las condiciones de cultivo, y también ampliar los estudios a otras especies animales. El posible papel de la ACh y de los receptores nicotínicos se ha de considerar con ciertas reservas, dados los hallazgos recientes de Gauda [29]. El papel de la DA tampoco está claro. En los experimentos con cocultivos los hallazgos de Zhong et al [48] sobre la farmacología dopaminérgica no se ajusta a las predicciones que cabría esperar si ésta fuera el neurotransmisor primario, pero tampoco podemos definir en términos sencillos en qué podría consistir su acción moduladora. No es fácil explicar el por qué de los altos contenidos de DA en las células quimiorreceptoras y su liberación en respuesta a los estímulos naturales sin suponerla un papel importante en la comunicación con las terminaciones sensoriales.

\section{BIBLIOGRAFÍA}

1. González C, Almaraz L, Obeso A, Rigual R. Arterial chemoreceptors. In Bittar E, ed. Pulmonary biology in health and disease. New York: Springer-Verlag. 2002. p. 114-40

2. Schmidt CF. Respiration. In Bard P, ed. McLeod's physiology in modern medicine ( $8^{\text {th }}$ ed.). St Louis: Mosby 1938. p. 469-619.

3. Marshall, EK, Rosenfeld M. Depression of respiration by oxygen. J Pharmacol Exp Ther 1936; 57: 437-57.

4. Zapata P. Chemosensory activity in the carotid nerve: Effects of physiological variables. In González C, ed. The carotid body chemoreceptors. New York: Springer-Verlag; 1997. p. 97-117.

5. Rigual R, Zapata P, González C. Respuestas sistémicas evocadas por la estimulación de los quimiorreceptores arteriales: funciones adaptativa y homeostática del cuerpo carotídeo. Rev Neurol 2003. In press.

6. González C, Almaraz L, Obeso A, Rigual R. Carotid body chemoreceptors: From natural stimuli to sensory discharges. Physiol Rev 1994; 74: 829-98.

7. González C. The carotid body chemoreceptors. New York: SpringerVerlag: 1997.

8. Taube HW. De vera nervi intercostalis origine. Göttingem: Vandenhoeck; 1743.

9. Luschka, H. Ueber die drüsenartige Natur des sogenannten Ganglion intercaroticum. Arch Anat Physiol Lpz 1862; 405-14.

10. De Castro F. Sur la structure et l'innervation de la glande intercarotidienne (glomus caroticum) de l'homme et des mammifères, et sur un nouveau système d'innervation autonome du nerf glossopharyngien. Trab Lab Invest Biol Univ Madrid 1926; 24: 365-432.

11. De Castro F. Sur la structure et l'innervation du sinus carotidien de l'homme et des mammifères: Nouveaux faits sur l'innervation et la fonction du glomus caroticum. Trab Lab Invest Biol Univ Madrid 1928; 25: $330-80$.

12. Heymans C, Bouckaert JJ, Dautrebande L. Sinus carotidien et réflexes respiratoires, II. Influences respiratoires réflexes de l'acidose, de l'alcalose, de l'anhydride carbonique, de l'ion hydrogene et de l'anoxémie: Sinus carotidiens et échanges respiratoires dans les poumons et au delà des poumons. Arch Int Pharmacodyn Ther 1930; 39: 400-8.

13. Heymans C, Bouckaert JJ, Dautrebande L. Sinus carotidien et réflexes respiratoires; sensibilité des sinus carotidiens aux substances chimiques. Action stimulante respiratoire réflexe du sulfure de sodium, du cyanure de potassium, de la nicotine et de la lobéline. Arch Int Pharmacodyn Ther 1931; 40: 54-91.

14. De Castro F. Sur la structure de la synapse dans les chemorecepteurs: Leur mécanisme d'excitation et rôle dans la circulation sanguine locale. Acta Physiol Scand 1951; 22: 14-43.

15. De Castro F, Rubio M. The anatomy and innervation of the blood vessels of the carotid body and the role of chemoreceptive reactions in the autoregulation of the blood flow. In Torrance RW, ed. Arterial chemroeceptors. Oxford: Blackwell Scientific Publications; 1968. p. 267-77.

16. Clarke JA, De Burgh Daly D, Ead HV. Comparison of the size of the vascular compartment of the carotid body of the fetal, neonatal and adult cat. Acta Anat Basel 1990; 138: 166-74.

17. Daly MB, Lambertsen CJ, Schweitzer A. Observations on the volume of blood flow and oxygen utilization of the carotid body in the cat. $\mathrm{J}$ Physiol Lond 1954; 125: 67-89.

18. Barnett S, Mulligan E, Wagerle LC, Lahiri S. Measurement of carotid body blood flow in cats by use of radioactive microspheres. J Appl Physiol 1988; 65: 2484-9.
19. Obeso A, Rocher A, Herreros B, González C. Oxygen consumption and energy metabolism of the carotid body. In González C, ed. The carotid body chemoreceptors. New York: Springer-Verlag;1997. p. 31-45.

20. Eyzaguirre C, Zapata P. Perspectives in carotid body research. J Appl Physiol 1984; 57: 931-57.

21. Nishi K, Stensaas LJ. The ultrastructure and source of nerve endings in the carotid body. Cell Tissue Res 1974; 154: 303-19.

22. McDonald DM. Peripheral chemoreceptors. Structure function relationships of the carotid body. In Hornbein TF, ed. Regulation of breathing. Part I. New York: Marcel Dekker, Inc; 1981. p. 105-319.

23. Verna A. The mammalian carotid body: Morphological data. In González $\mathrm{C}$, ed. The carotid body chemoreceptors. New York: Springer-Verlag. 1997. p. 1-30.

24. Wang ZZ, Stensaas LJ, Dinger BG, Fidone SJ. Nitric oxide mediates chemoreceptor inhibition in the cat carotid body. Neuroscience 1995; 65: 217-29.

25. González C, Dinger B, Fidone S. Functional Significance of chemoreceptor cells neurotransmitters. In González $\mathrm{C}$, ed. The carotid body chemoreceptors. New York: Springer-Verlag; 1997. p. 47-63.

26. Rigual R, Rico AJ, Prieto-LLoret J, De Felipe C, González C, Donnelly DF. Chemoreceptor activity is normal in mice lacking NK1 receptor. Eur J Neurosci 2002; 16: 2078-84.

27. Gauda EB, Bamford OS, Northington FJ. Lack of induction of substance $\mathrm{P}$ gene expression by hypoxia and absence of neurokinin 1-receptor $\mathrm{mR}$ NAs in the rat carotid body. J Auton Nerv Syst 1998; 74: 100-8.

28. Gauda EB, Lawson EE. Developmental influences on carotid body responses to hypoxia. Respir Physiol 2000; 121: 199-208.

29. Gauda EB. Gene expression in peripheral arterial chemoreceptors. Microsc Res Tech 2002; 59: 153-67.

30. Fidone SJ, Weintraub ST, Stavinoha WB. Acetylcholine content of normal and denervated cat carotid bodies measured by pyrolysis gas chromatography/mass fragmentometry. J Neurochem 1976; 26: 1047-9.

31. Hellstrom S. Putative neurotransmitters in the carotid body. Mass fragmentographic studies. Adv Biochem Psychopharmacol 1977; 16: 257-63.

32. Almaraz L. Neurotransmisores en el proceso de quimiorrecepción. Tesis Doctoral. Valladolid: Universidad de Valladolid; 1983.

33. De Castro F. Nuevas observaciones sobre la inervación de la región carotídea. Los quimio y presorreceptores. Trab Lab Invest Biol Univ Madrid 1940; 32: 297-384.

34. Biscoe TJ, Stehbens WE. Ultrastructure of the carotid body. J Cell Biol 1966; 30: 563-78.

35. Biscoe TJ. Carotid body: structure and function. Physiol Rev 1971; 51: 437-95.

36. Hess A, Zapata Z. Innervation of the cat carotid body: normal and experimental studies. Fed Proc 1972; 31: 1365-82.

37. Holton P, Wood JB. The effects of bilateral removal of the carotid bodies and denervation of the carotid sinuses in two human subjects. J Physiol 1965; 181: 365-78

38. Honda Y, Myojo S, Hasegawa S, Hasegawa T, Severinghaus JW. Decreased exercise hyperpnea in patients with bilateral carotid chemoreceptor resection. J Appl Physiol 1979; 46: 908-12.

39. Honda Y. Role of carotid chemoreceptors in control of breathing at rest and in exercise: studies on human subjects with bilateral carotid body resection. Jpn J Physiol 1985; 35: 535-44.

40. Honda Y. Respiratory and circulatory activities in carotid body resected humans. J Appl Physiol 1992; 73: 1-8.

41. Chiocchio SR, Hilton SM, Tramezzani JH, Willshaw P. Loss of periph- 
eral chemoreflexes to hypoxia after carotid body removal in the rat. Respir Physiol 1984; 57: 235-46.

42. Verna A, Roumy R, Leitner LM. Loss of chemoreceptive properties of the rabbit carotid body after destruction of the glomus cells. Brain Res 1975; 100: 13-23.

43. Monti-Bloch L, Stensaas LJ, Eyzaguirre C. Effects of ischemia on the function and structure of the cat carotid body. Brain Res 1983;270: 63-76.

44. Zapata P, Stensaas LJ, Eyzaguirre C. Axon regeneration following a lesion of the carotid nerve: electrophysiological and ultrastructural observations. Brain Res 1976; 113: 235-53.

45. Zapata P, Hess A, Eyzaguirre C. Reinnervation of carotid body and sinus with superior laryngeal nerve fibers. J Neurophysiol 1969; 32: 215-28.

46. Monti-Bloch L, Stensaas LJ, Eyzaguirre C. Carotid body grafts induce chemosensitivity in muscle nerve fibers of the cat. Brain Res 1983; 270: 77-92.

47. Alcayaga J, Eyzaguirre C. Electrophysiological evidence for the reconstitution of chemosensory units in co-cultures of carotid body and nodose ganglion neurons. Brain Res 1990; 534: 324-8.

48. Zhong H, Zhang M, Nurse CA. Synapse formation and hypoxic signalling in co-cultures of rat petrosal neurones and carotid body type 1 cells. J Physiol 1997; 503: 599-612.

49. Alcayaga J, Varas R, Arroyo J, Iturriaga R, Zapata P. Responses to hypoxia of petrosal ganglia in vitro. Brain Res 1999; 845: 28-34.

50. Zapata P . From oxygen sensing to chemosensory activity: The mediator role of glomus cells. In Lahiri S, Prabhakar Nr, Semenza G, eds. Oxygen sensing: Responses and adaptations to hypoxia. Lung biology in health and disease. New York: M Dekker; 2003. In press.

51. Grundfest $\mathrm{H}$. The electrophysiology of input membrane in electrogenic excitable cells. In Loewenstein RW, ed. Handbook of sensory physiology. Principles of receptor physiology. New York: Springer Verlag; 1971. p.135-65.

52. Anichkov SV, Belen'kii ML. Pharmacology of the carotid body chemoreceptors. New York: Macmillan; 1963.

53. Coxon RV. Regulation of biochemical reactions by oxygen and carbon dioxide. In Torrance RW, ed. Arterial chemoreceptors. Oxford: Blackwell Scientific Publications; 1968. p. 91-102.

54. Lubbërs DW, Teckhaus L, Seidl E. Capillary distances and oxygen supply to the specific tissue of the carotid body. In Acker H, Fidone S, Eyzaguirre C, Lübbers DW, Torrance RW, eds. Chemoreception in the carotid body. BerlIn Springer Verlag; 1977. p. 62-8.

55. Obeso A, Almaraz L, González C. Correlation between adenosine triphosphate levels, dopamine release and electrical activity in the carotid body: support for the metabolic hypothesis of chemoreception. Brain Res 1985; 348: 64-8.

56. Verna A, Talib N, Roumy M, Pradet A. Effects of metabolic inhibitors and hypoxia on the ATP, ADP and AMP content of the rabbit carotid body in vitro: the metabolic hypothesis in question. Neurosci Lett 1990; 116: 156-61

57. Obeso A. Hipótesis metabólica de quimiotransducción: hechos experimentales. Tesis Doctoral. Valladolid: Universidad de Valladolid, 1984.

58. Obeso A, Almaraz L, González C. Effects of cyanide and uncouplers on chemoreceptor activity and ATP content of the cat carotid body. Brain Res 1989; 481: 250-57.

59. Krylov SS, Anichkov HS. The effects of metabolic inhibitors on carotid chemoreceptors. In Torrance RW, ed. Arterial chemoreceptors. Oxford: Blackwell; 1968. p. 103-13.

60 . Winder CV. On the mechanisms of stimulation of carotid gland chemoreceptor. Am J Physiol 1937; 118: 389-98.

61. Torrance RW. Arterial chemoreceptors. In Widdicombe JG, ed. Respiratory physiology. Baltimore: University Park Press; 1974. p. 247-71.

62. Torrance RW. A new version of the acid hypothesis receptor hypothesis of carotid chemoreceptors. In Paintal AS, ed. Morphology and mechanisms of chemoreceptors. Delhi: Navchetan Press; 1976. p. 131-7.

63. Hanson MA, Nye PC, Torrance RW. The exodus of an extracellular bicarbonate theory of chemoreception and the genesis of an intracellular one. In Belmonte C, Pallot DJ, Acker H, Fidone S, eds. Arterial chemoreceptors . Leicester: Leicester University Press; 1981. p. 403-16.

64. Lahiri S, Mulligan E, Mokashi A. Adaptive response of carotid body chemoreceptors to $\mathrm{CO}_{2}$. Brain Res 1982; 234: 137-47.

65. Fidone S, González C. Initiation and control of chemoreceptor activity in the carotid body. In Fishman AP, ed. Handbook of physiology. The respiratoy system. Bethesda: Amer Physiol Soc; 1986. p. 247-312.

66. McCloskey DI. Carbon dioxide and the carotid body. In Torrance RW, ed. Arterial chemoreceptors. Oxford: Blackwell Scientific Publications; 1968. p. 279-95.

67. Rigual R, Íñiguez C, Carreres C, González C. Carbonic anhydrase in the carotid body and the carotid sinus nerve. Histochemistry $1985 ; 82$ : 577-80.

68. González $\mathrm{C}$, Fidone $\mathrm{S}$. Increased release of ${ }^{3} \mathrm{H}$ dopamine during low $\mathrm{O}_{2}$ stimulation of rabbit carotid body in vitro. Neurosci Lett 1977; 6: 95-9.
69. González C, Kwok Y, Gibb J, Fidone S. Effects of hypoxia on tyrosine hydroxylase activity in rat carotid body. J Neurochem. 1979; 33: 713-9.

70. González C, Kwok Y, Gibb JW, Fidone SJ. Reciprocal modulation of tyrosine hydroxylase activity in rat carotid body. Brain Res 1979; 172: 572-6.

71. González C, Kwok Y, Gibb J, Fidone S. Physiological and pharmacologic effects on TH activity in rabbit and cat carotid body. Am J Physiol 1981; 240: R38-43.

72. Fidone S, González S. Catecholamine synthesis in rabbit carotid body in vitro. J Physiol Lond 1982; 333: 69-79.

73. Fidone S, González C, Yoshizaki K. Effects of hypoxia on catecholamine synthesis in rabbit carotid body in vitro. J Physiol Lond 1982; 333: 81-91.

74. Fidone S, González S, Yoshizaki K. Effects of low oxygen on the release of dopamine from the rabbit carotid body in vitro. J Physiol Lond 1982; 333: 93-110.

75. Rigual R, González E, González C, Fidone S. Synthesis and release of catecholamines by the cat carotid body in vitro: effects of hypoxic stimulation. Brain Res 1986; 374: 101-9.

76. Vicario I, Rigual R, Obeso A, González C. Characterization of the synthesis and release of catecholamine in the rat carotid body in vitro. Am J Physiol 2000; 278: C490-9.

77. Almaraz L, González C, Obeso A. Effects of high potassium on the release of $\left[{ }^{3} \mathrm{H}\right]$ dopamine from the cat carotid body in vitro. J Physiol Lond 1986; 379: 293-307.

78. Obeso A, Rocher A, Fidone S, González C. The role of dihydropyridine sensitive $\mathrm{Ca}^{2+}$ channels in stimulus evoked catecholamine release from chemoreceptor cells of the carotid body. Neuroscience 1992; 47: 463-72.

79. Rocher A. Vías de entrada de calcio y transducción sensorial en las células quimiorreceptoras del cuerpo carotídeo. Tesis Doctoral. Valladolid: Universidad de Valladolid, 1989.

80. Rocher A, Obeso A, Herreros B, González C. Activation of the release of dopamine in the carotid body by veratridine. Evidence for the presence of voltage dependent $\mathrm{Na}^{+}$channels in type I cells. Neurosci Lett 1988; 94: 274-8.

81. Rocher A, Obeso A, Cachero TG, Herreros B, González C. Participation of Na channels in the response of carotid body chemoreceptor cells to hypoxia. Am J Physiol 1994; 267: C738-44.

82. Obeso A, González C, Dinger B, Fidone S. Metabolic activation of carotid body glomus cells by hypoxia. J Appl Physiol 1989; 67: 484-7.

83. Obeso A, González C, Rigual R, Dinger B, Fidone S. Effect of low $\mathrm{O}_{2}$ on glucose uptake in rabbit carotid body. J Appl Physiol 1993; 74: 2387-93.

84. Yarowsky P, Ingvar OH. Neuronal activity and energy metabolism. Fed Proc 1981; 40: 2353-62.

85. Pérez García MT, Obeso A, López López JR, Herreros B, González C. Characterization of chemoreceptor cells in primary culture isolated from adult rabbit carotid body. Am J Physiol 1992; 263: C1152-9.

86. López Barneo J, López López JR, Ureña J, González C. Chemotransduction in the carotid body: $\mathrm{K}^{+}$current modulated by $\mathrm{Po}_{2}$ in type $\mathrm{I}$ chemoreceptor cells. Science 1988; 241: 580-2.

87. López López J, González C, Ureña J, López Barneo J. Low $\mathrm{Po}_{2}$ selectively inhibits $\mathrm{K}$ channel activity in chemoreceptor cells of the mammalian carotid body. J Gen Physiol 1989; 93: 1001-15.

88. Peers C. Hypoxic suppression of $\mathrm{K}^{+}$currents in type I carotid body cells: selective effect on the $\mathrm{Ca}^{2+}$ activated $\mathrm{K}^{+}$current. Neurosci Lett 1990; 119: 253-6.

89. López-López JR, González C, Pérez-García MT. Properties of ionic currents from isolated adult rat carotid body chemoreceptor cells: effect of hypoxia. J Physiol 1997; 499: 429-41.

90. Riesco-Fagundo AM, Pérez-García MT, González C, López-López JR. $\mathrm{O}_{2}$ modulates large-conductance $\mathrm{Ca}(2+)$-dependent $\mathrm{K}(+)$ channels of rat chemoreceptor cells by a membrane-restricted and $\mathrm{CO}$-sensitive mechanism. Circ Res 2001; 89: 430-6.

91. Buckler KJ. A novel oxygen-sensitive potassium current in rat carotid body type I cells. J Physiol 1997; 498: 649-62.

92. Buckler KJ. Background leak $\mathrm{K}^{+}$-currents and oxygen sensing in carotid body type 1 cells. Respir Physiol 1999; 115: 179-87.

93. Buckler KJ, Williams BA, Honore E. An oxygen-, acid- and anaesthetic-sensitive TASK-like background potassium channel in rat arterial chemoreceptor cells. J Physiol 2000; 525: 135-42.

94. Chou CL, Shirahata M. Two types of voltage-gated K channels in carotid body cells of adult cats. Brain Res 1996; 742: 34-42.

95. González C, Almaraz L, Obeso A, Rigual R. Oxygen and acid chemoreception in the carotid body chemoreceptors. Trends Neurosci 1992; 15: 146-53.

96. López López JR, González C. Time course of $\mathrm{K}^{+}$current inhibition by low oxygen in chemoreceptor cells of adult rabbit carotid body: effects of carbon monoxide. FEBS Lett 1992; 299: 251-4.

97. Pérez-García MT, López-López JR, González C. Kvß1.2 subunit coexpression in HEK293 cells confers $\mathrm{O}_{2}$ sensitivity to $\mathrm{Kv} 4.2$ but not to Shaker channels. J Gen Physiol 1999; 113: 897-907. 
98. Lewis A, Peers C, Ashford ML, Kemp PJ. Hypoxia inhibits human recombinant large conductance, $\mathrm{Ca}(2+)$-activated $\mathrm{K}(+)$ (maxi-K) channels by a mechanism which is membrane delimited and $\mathrm{Ca}(2+)$ sensitive. J Physiol 2002; 540: 771-80.

99. Jaggar JH, Leffler CW, Cheranov SY, Tcheranova D, Cheng X. Carbon monoxide dilates cerebral arterioles by enhancing the coupling of $\mathrm{Ca}^{2+}$ sparks to $\mathrm{Ca}^{2+}$-activated $\mathrm{K}^{+}$channels. Circ Res 2002; 91: 610-7.

100. Ganfornina MD, López Barneo J. Single $\mathrm{K}^{+}$channels in membrane patches of arterial chemoreceptor cells are modulated by $\mathrm{O}_{2}$ tension. Proc Natl Acad Sci USA 1991; 88: 2927-30.

101. Schafer FQ, Buettner GR. Redox environment of the cell as viewed through the redox state of the glutathione disulfide/glutathione couple. Free Radic Biol Med 2001; 30: 1191-212.

102. Chandel NS, Schumacker PT. Cellular oxygen sensing by mitochondria: old questions, new insight. J Appl Physiol 2000; 88: 1880-9.

103. Cross, AR, Henderson L, Jones OT, Delpiano MA, Hentschel J, Acker

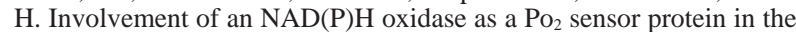
rat carotid body. Biochem J 1990; 272: 743-7.

104. Cheng G, Cao Z, Xu X, Van Meir EG, Lambeth JD. Homologs of gp91phox: cloning and tissue expression of Nox3, Nox4, and Nox5. Gene 2001; 269: 131-40.

105. Griendling KK, Sorescu D, Ushio-Fukai M. NAD(P)H oxidase: role in cardiovascular biology and disease. Circ Res 2000; 86: 494-501.

106. González C. Sensitivity to physiological hypoxia. In Weir EK, LópezBarneo J, eds. Oxygen regulation of oon channels and gene expression. New York: Futura Publishing Co, Inc. Armonk; 1998. p. 321-36.

107. González C, Sanz-Alfayate G, Agapito MT, Gómez-Niño A, Rocher A, Obeso A. Significance of ROS in oxygen sensing in cell systems with sensitivity to physiological hypoxia. Respir Physiol Neurobiol 2002; 132: 17-41.

108. González C, Agapito MT, Rocher A, Obeso A. Biology of reactive oxygen species. Their role in oxygen chemoreception in the carotid body. In Lahiri S, Semenza G, Prabhakar N, eds. Oxygen sensing: Responses and adaptations to hypoxia. New York: Marcel Dekker Inc; 2003. In press.

109. Sanz-Alfayate G, Obeso A, Agapito, MT, González C. Reduced to oxidized glutathione ratios and oxygen sensing in calf and rabbit carotid body chemoreceptor cells. J Physiol 2001; 537: 209-20.

110. Coppock EA, Martens JR, Tamkun MM. Molecular basis of hypoxiainduced pulmonary vasoconstriction: role of voltage-gated $\mathrm{K}^{+}$channels. Am J Physiol Lung Cell Mol Physiol 2001; 281: L1-12.

111. López López JR, de Luis A, González C. Properties of a transient $\mathrm{K}^{+}$ current in chemoreceptor cells of rabbit carotid body. J. Physiol Lond 1993; 460: 15-32.

112. Pérez García MT, González C. Mechanisms of sensory transduction in chemoreceptor cells: the role of second messengers. In González C, ed. The carotid body chemoreceptors. New York: Springer-Verlag. 1997. p 79-96.

113. Donnelly DF. Are oxygen dependent $\mathrm{K}^{+}$channels essential for carotid body chemo-transduction? Respir Physiol 1997; 110: 211-8.

114. Lahiri S, Roy A, Rozanov C, Mokashi A. $\mathrm{K}^{+}$-current modulated by $\mathrm{PO}_{2}$ in type I cells in rat carotid body is not a chemosensor. Brain Res 1998; 794: $162-5$.

115. Pardal R, Ludewig U, García-Hirschfeld J, López-Barneo J. Secretory responses of intact glomus cells in thin slices of rat carotid body to hypoxia and tetraethylammonium. Proc Natl Acad Sci USA 2000; 97: 2361-6.

116. Yamamoto Y, Kummer W, Atoji Y, Suzuki Y. TASK-1, TASK-2, TASK-3 and TRAAK immunoreactivities in the rat carotid body. Brain Res 2002; 950: 304

117. Pérez-García MT, López-López JR, Riesco A M, Hoppe U, González C, Marban E, Johns DC. Supression of transient outward $\mathrm{K}^{+}$currents in chemoreceptor cells of the rabbit carotid body by viral gene transfer of inducible dominant negative Kv4.3 constructs. J Neurosci 2000; 20: 5689-95.

118. Sánchez D, López-López JR, Pérez-García MT, Sanz-Alfayate G, Obeso A, Ganfornina MD, González C. Molecular identification of Kvalpha subunits that contribute to the oxygen-sensitive $\mathrm{K}(+)$ current of chemoreceptor cells of the rabbit carotid body. J Physiol 2002; 542: 369-82.

119. Rigual R, López López JR, González C. Release of dopamine and chemoreceptor discharge induced by low $\mathrm{pH}$ and high $\mathrm{PcO}_{2}$ stimulation of the cat carotid body. J Physiol Lond 1991; 433: 519-31.

120. Buckler KJ, Vaughan Jones RD, Peers C, Lagadic Gossmann D, Nye PC. Effects of extracellular $\mathrm{pH}, \mathrm{PcO}_{2}$ and $\mathrm{HCO}_{3}^{-}$on intracellular $\mathrm{pH}$ in isolated type I cells of the neonatal rat. J Physiol Lond 1991; 444: 703-21.

121. Buckler KJ, Vaughan-Jones RD, Peers C, Nye PC. Intracellular pH and its regulation in isolated type I carotid body cells of the neonatal rat. J Physiol Lond 1991; 436: 107-29.

122. Rocher A, Obeso A, González C, Herreros B. Ionic mechanisms for the transduction of acidic stimuli in rabbit carotid body glomus cells. J Physiol Lond 1991; 433: 533-48.

123. Summers BA, Overholt JL, Prabhakar NR. CO(2) and $\mathrm{pH}$ independent- ly modulate L-type $\mathrm{Ca}(2+)$ current in rabbit carotid body glomus cells J Neurophysiol 2002; 88: 604-12.

124. Russell JM, Boron WF, Brodwick MS. Intracellular $\mathrm{pH}$ and Na fluxes in barnacle muscle with evidence for reversal of the ionic mechanism of intracellular $\mathrm{pH}$ regulation. J Gen Physiol 1983; 82: 47-78.

125. Buckler KJ, Vaughan Jones RD. Effects of acidic stimuli on intracellular calcium in isolated type I cells of the neonatal rat carotid body. Pflugers Arch 1993; 425: 22-7.

126. Buckler KJ, Vaughan-Jones RD. Effects of hypercapnia on membrane potential and intracellular calcium in rat carotid body type I cells. J Physiol 1994; 478: 157-71.

127. Buckler KJ, Vaughan-Jones RD. Effects of hypoxia on membrane potential and intracellular calcium in rat neonatal carotid body type I cells. J Physiol 1994; 476: 423-8.

128. Fitzgerald RS, Parks DC. Effect of hypoxia on carotid chemoreceptor response to carbon dioxide in cats. Respir Physiol 1971; 12: 218-29.

129. Torrance RW. Prolegomena. In Torrance RW, ed. Arterial chemoreceptors. Oxford: Blackwell Scientific Publication; 1968. p. 1-40.

130. Peers $\mathrm{C}$, Green FK. Inhibition of $\mathrm{Ca}^{2+}$ activated $\mathrm{K}^{+}$currents by intracellular acidosis in isolated type I cells of the neonatal rat carotid body. $\mathrm{J}$ Physiol Lond 1991; 437: 589-602.

131. Schweitzer A, Wright S. Action of prostigmine and acetylcholine on respiration. Q J Exp Physiol 1938; 28: 33-47.

132. Liljestrand G. Transmission at chemoreceptors. Phramacol Rev 1954; 6: 73-8.

133. Douglas WW. Is there chemical transmission at chemoreceptors? Pharmacol Rev 1954; 6: 81-3.

134. Heymans C, Neil E. Reflexogenic areas of the cardiovascular system. London: Churchill; 1958.

135. Eyzaguirre C, Zapata P. A discussion of possible transmitter or generator substances in carotid body chemoreceptors. In Torrance RW, ed Arterial chemoreceptors. Oxford: Blackwell Scientific Publications; 1968. p. 213-51.

136. Lever JD Boyd JD. Osmiophile granules in glomus cells of the rabbit carotid body. Nature London 1957; 179: 1082-3.

137. Chiocchio SR, Biscardi AM, Tramezzani, GH. 5 hydroxytryptamine in the carotid body of the cat. Science 1967; 158: 790-1.

138. McQueen DS, Evrard Y. Use of selective antagonists for studying the role of putative transmitters in chemoreception. In Eyzaguirre $\mathrm{C}, \mathrm{Fi}$ done SJ, Fitzgerald RS, Lahiri S, McDonald DM, eds. Arterial chemoreception. New York: Springer Verlag; 1990. p. 168-73.

139. Prabhakar NR, Gauda E, Cheniack NS. The mechanism of action of tachykinins in the carotid body. In Eyzaguirre C, Fidone SJ, Fitzgerald RS, Lahiri S, McDonald DM, eds. Arterial chemoreception. New York: Springer Verlag; 1990. p. 192-8.

140. Prabhakar NR, Kou Yur, Runold M. Chemoreceptor responses to substance P, physalaemin and eledoisin: evidence for neurokinin 1 receptors in the cat carotid body. Neurosci Lett 1990; 120: 183-6.

141. Zapata P. Chemosensory activity in the carotid nerve: Effects of pharmacological agents. In González $\mathrm{C}$, ed. The carotid body chemoreceptors. New York: Springer-Verlag; 1997. p. 119-46.

142. González Guerrero P, Rigual R, González C. Opioid peptides in the rabbit carotid body: Identification and evidence for co utilization and interactions with dopamine. J Neurochem 1993; 60: 1762-8.

143. Eyzaguirre C, Lewin J. Effect of different oxygen tensions on the carotid body in vitro. J Physiol 1961; 159: 238-50.

144. McLennan H. Synaptic transmision. Philadelphia: Saunders; 1963

145. Wang ZZ, Stensaas LJ, Dinger B, Fidone SJ. Immunocytochemical localization of choline acetyltransferase in the carotid body of the cat and rabbit. Brain Res 1989; 498: 131-4.

146. Nurse CA, Zhang M. Acetylcholine contributes to hypoxic chemotransmission in co-cultures of rat type 1 cells and petrosal neurons. Respir Physiol 1999; 115: 189-99.

147. Fitzgerald RS. Oxygen and carotid body chemotransduction: the cholinergic hypothesis - a brief history and new evaluation. Respir Physio 2000; 120: 89-104.

148. Zigmond RE, Hyatt-Sachs H, Baldwin C, Qu XM, Sun Y, McKeon TW et al Phenotypic plasticity in adult sympathetic neurons: changes in neuropeptide expression in organ culture. Proc Natl Acad Sci USA 1992; 89: 1507-11.

149. Schutz B, Schafer MK, Eiden LE, Weihe E. Vesicular amine transporter expression and isoform selection in developing brain, peripheral nervous system and gut. Brain Res Dev Brain Res 1998; 106: 181-204.

150. Donoso A, Zapata P, Álvarez J. Incorporation of tritiated choline by the carotid body incubated in vitro Arch Biol Med Exp 1970; 7: 1-7.

151. Fidone S, Weintraub S, Stavinoha W, Stirling C, Jones L. Endogenous acetylcholine levels in cat carotid body and the autoradiographic localization of a high affinity component of choline uptake. In Acker H, Fidone S, Pallot D, Eyzaguirre C, Lübbers DW, Torrance RW, eds. Chemoreception in the carotid body. Berlin: Springer Verlag; 1977. p. 106-13. 
152. Eyzaguirre C, Koyano H, Taylor JR. Presence of acetylcholine and transmitter release from carotid body chemoreceptors. J Physiol Lond 1965; 178: 463-76.

153. Eyzaguirre $C$, Zapata $P$. The release of acetylcholine from carotid body tissues. Further study on the effects of acetylcholine and cholinergic blocking agents on the chemosensory discharge. J Physiol Lond 1968; 195: 589-607.

154. Fitzgerald RS, Shirahata M. Release of acetylcholine from the in vitro cat carotid body. Adv Exp Med Biol 1996; 410: 227-32.

155. Fitzgerald RS, Shirahata M, Wang HY. Acetylcholine is released from in vitro cat carotid bodies during hypoxic stimulation. Adv Exp Med Biol. 2000; 475: 485-94.

156. Fitzgerald RS, Shirahata M, Wang HY. Acetylcholine release from cat carotid bodies. Brain Res 1999; 841: 53-61.

157. Dinger BG, González C, Yoshizaki K, Fidone S. Alpha bungarotoxin binding in cat carotid body. Brain Res 1981; 205: 187-93.

158. Dinger B, González C, Yoshizaki K, Fidone S. Localization and function of cat carotid body nicotinic receptors. Brain Res 1985; 339: 295-304.

159. Obeso A, Gómez-Niño MA, Almaraz L, Dinger B, Fidone S, González C. Evidence for two types of nicotinic receptors in the cat carotid body chemoreceptor cells. Brain Res 1997; 754: 298-302.

160. Shirahata M, Ishizawa Y, Rudisill M, Schofield B, Fitzgerald RS. Presence of nicotinic acetylcholine receptors in cat carotid body afferent system. Brain Res 1998; 814: 213-17.

161. Dinger BG, Hirano T, Fidone SJ. Autoradiographic localization of muscarinic receptors in rabbit carotid body. Brain Res 1986; 367: 328-31.

162. Dinger BG, Almaraz L, Hirano T, Yoshizaki K, González C, Gómez Niño A, Fidone SJ. Muscarinic receptor localization and function in rabbit carotid body. Brain Res 1991; 562: 190-198.

163. Hirano T, Dinger B, Yoshizaki K, González C, Fidone S. Nicotinic versus muscarinic binding sites in cat and rabbit carotid bodies. Biol Signals 1992; 1: 143-9.

164. Fitzgerald S, Shirahata M, Ide T Further cholinergic aspect of carotid body chemotransduction of hypoxia in cats. J Appl Physiol 1997; 82: 819-27.

165. González C, Pérez García MT, Mintenig GM, Gual A. Transmisión sináptica por neurotransmisores múltiples. Cotransmisión en el cuerpo carotídeo. In Esquerda JE, Gallego R, Gual A, Ramírez G, Rubia F, eds. Neurotranmisión y plasticidad sináptica. Barcelona: Espaxs. 1991. p. 109-28.

166. Zhang M, Zhong H, Vollmer C, Nurse CA. Co-release of ATP and ACh mediates hypoxic signalling at rat carotid body chemoreceptors. J Physiol 2000; 525: 143-58.

167. Nurse CA, Zhang M. Synaptic mechanisms during re-innervation of rat arterial chemoreceptors in co-culture. Comp Biochem Physiol A Mol Integr Physiol 2001; 130: 241-51.

168. Prasad M, Fearon IM, Zhang M, Laing M, Vollmer C, Nurse CA. Expression of $\mathrm{P} 2 \mathrm{X} 2$ and $\mathrm{P} 2 \mathrm{X} 3$ receptor subunits in rat carotid body afferent neurones: role in chemosensory signalling. J Physiol. 2001; 537: 667-77.

169. Steele RH, Hinterberger H. Catecholamines and 5 hydroxytryptamine in the carotid body in vascular, respiratory, and other diseases. J Lab Clin Med 1972; 80: 6370.

170. Lack EE, Pérez-Atayde AR, Young JB. Carotid body hyperplasia in cystic fibrosis and cyanotic heart disease. A combined morphometric, ultrastructural, and biochemical study. Am J Pathol 1985; 119: 301-14.

171. Belmonte C, González C, García AG. Dopamine beta hydroxylase activity in the cat carotid body. In Acker H, Fidone S, Pallot D, Eyzaguirre C, Lübbers DW, Torrance RW, eds. Chemoreception in the carotid body. Berlin; Springer Verlag; 1977. p. 99105.

172. González E, Rigual R, Fidone SJ, González C. Mechanisms for termination of the action of dopamine in carotid body chemoreceptors. J Auton Nerv Syst 1987; 18: 249-59.

173. Czyzyk Krzeska MF, Bayliss DA, Lawson EE, Millhorn DE. Regulation of tyrosine hydroxylase in the rat carotid body by hypoxia. J Neurochem 1992; 58: 1538-46.

174. Zuazo A, Zapata Z. Effects of 6 hydroxy dopamine on carotid body chemosensory activity. Neurosci Lett 1978; 9: 323-8.

175. Dinger B, González C, Yoshizaki K, Fidone S. [ $\left.{ }^{3} \mathrm{H}\right]$ Spiroperidol binding in normal and denervated carotid bodies. Neurosci Lett 1981; 21: $51-5$.

176. Almaraz L, Pérez García MT, González C. Presence of D1 receptors in the rabbit carotid body. Neurosci Lett 1991; 132: 259-62.

177. Verna A, Schamel A, Le Moine C, Bloch B. Localization of dopamine $\mathrm{D} 2$ receptor mRNA in glomus cells of the rabbit carotid body by in situ hybridization. J Neurocytol 1995; 24: 265-70.

178. Bairam A, Khandjian EW. Expression of dopamine D2 receptor mRNA isoforms in the carotid body of rat, cat and rabbit. Brain Res 1997; 760: $287-9$.
179. Bairam A, Frenette J, Dauphin C, Carroll JL, Khandjian EW. Expression of dopamine D1-receptor mRNA in the carotid body of adult rabbits cats and rats. Neurosci Res 1998; 31: 147-54.

180. Huey KA, Powell FL. Time-dependent changes in dopamine D(2)-receptor mRNA in the arterial chemoreflex pathway with chronic hypoxia. Brain Res Mol Brain Res 2000; 75: 264-70.

181. Hanbauer I, Hellstrom S. The regulation of dopamine and noradrenaline in the rat carotid body and its modification by denervation and by hypoxia. J Physiol Lond 1978; 282: 21-34.

182. Rigual R, González E, Fidone S, González C. Effects of low pH on synthesis and release of catecholamines in the cat carotid body in vitro. Brain Res 1984; 309: 178-81.

183. Obeso A, Almaraz L, González C. Effects of 2-deoxy-D-glucose on in vitro cat carotid body. Brain Res. 1986; 371: 25-36.

184. Gómez Niño A, Dinger B, González C, Fidone SJ. Differential stimulus coupling to dopamine and norepinephrine stores in rabbit carotid body type I cells. Brain Res 1990; 525: 160-4.

185. Gómez Niño A, López López JR, Almaraz L, González C. Inhibition of ${ }^{3} \mathrm{H}$ catecholamine release and $\mathrm{Ca}^{2+}$ currents by prostaglandin $\mathrm{E}_{2}$ in the rabbit carotid body chemoreceptor cells. J Physiol Lond 1994; 476: 269-77.

186. Pérez García MT, Almaraz L, González C. Cyclic AMP modulates differentially the release of dopamine induced by hypoxia and other stimuli and increases dopamine synthesis in the rabbit carotid body. J Neurochem 1991; 57: 1992-2000.

187. Donnelly DF. Electrochemical detection of catecholamine release from rat carotid body in vitro. J Appl Physiol 1993; 74: 2330-7.

188. Buerk DG, Lahiri S, Chugh D, Mokashi A. Electrochemical detection of rapid DA release kinetics during hypoxia in perfused-superfused cat carotid body. J Appl Physiol 1995; 78: 830-7.

189. Iturriaga R, Alcayaga J, Zapata P. Dissociation of hypoxia-induced chemosensory responses and catecholamine efflux in cat carotid body superfused in vitro. J Physiol 1996; 497: 551-64.

190. Rigual R, Almaraz L, González C, Donnelly DF. Developmental changes in chemoreceptor nerve activity and catecholamine secretion in rabbit carotid body: possible role of $\mathrm{Na}+$ and $\mathrm{Ca} 2+$ currents. Pflugers Arch 2000; 439: 463-70.

191. Montoro RJ, Urena J, Fernández-Chacón R, Álvarez de Toledo G, López-Barneo J. Oxygen sensing by ion channels and chemotransduction in single glomus cells. J Gen Physiol 1996; 107: 133-43.

192. Carpenter E, Hatton CJ, Peers C. Effects of hypoxia and dithionite on catecholamine release from isolated type I cells of the rat carotid body. J Physiol 2000; 523: 719-29.

193. Donnelly DF. Does catecholamine secretion mediate the hypoxia induced increase in nerve activity? Biol Signals 1995; 4: 304-9.

194. Donnelly DF. Chemoreceptor nerve excitation may not be proportional to catecholamine secretion. J Appl Physiol. 1996; 81: 657-64.

195. Artalejo AR, García AG, Montiel C, Sánchez García P. A dopaminergic receptor modulates catecholamine release from the cat adrenal gland. J Physiol 1985; 362: 359-68.

196. García AG, Kirpekar SM, Sánchez García P. Release of noradrenaline from the cat spleen by nerve stimulation and potassium. J Physiol 1976; 261: 301-17.

197. Fuder H, Muscholl E, Wegwart R. The effects of methacholine and calcium deprivation on the release of the false transmitter alfa methyladrenaline from the isolated rabbit heart. Naunyn Schmiedeberg's Arch Pharmacol 1976; 293: 225-34.

198. Wakade AR, Kruz J. Effect of reserpine, phenoxybenzamine and cocaine on neuromuscular transmission in the vas deferens of the guinea pig. J Pharmacol Exp Ther 1972; 181: 310-7.

199. Fidone S, González C, Dinger B, Gómez Niño A, Obeso A, Yoshizaki $\mathrm{K}$. Cellular aspects of peripheral chemoreceptor function. In Crystal RG, West JB, eds. The lung. Scientific foundations. New York: Raven Press; 1991: 1319-32.

200. Alcayaga J, Varas R, Arroyo J, Iturriaga R, Zapata P. Dopamine modulates carotid nerve responses induced by acetylcholine on the cat petrosal ganglion in vitro. Brain Res. 1999; 831: 97-103.

201. McQueen DS. Pharmacological aspects of putative transmitters in the carotid body. In: Acker H and O'Regan RG, eds. Physiology of the peripheral arterial chemoreceptors. Amsterdam: Elsevier; 1983. p. 149-95.

202. Zapata P. Effects of dopamine on carotid chemo and baroreceptors in vitro. J Physiol Lond 1975; 244: 235-51.

203. Docherty RJ, McQueen DS. Inhibitory action of dopamine on cat carotid chemoreceptors. J Physiol Lond 1978; 279: 425-36.

204. Lahiri S, Nishino T. Inhibitory and excitatory effects of dopamine on carotid chemoreceptors. Neurosci Lett 1980; 20: 313-8.

205. Llados F, Zapata P. Effects of dopamine analogues and antagonists on carotid body chemosensors in situ. J Physiol 1978; 274: 487-99.

206. Nishi K. A pharmacologic study on a possible inhibitory role of dopam- 
ine in the cat carotid body chemoreceptor. In Acker H, Fidone S, Pallot D, Eyzaguirre C, Lübbers DW, Torrance RW, eds. Chemoreception in the carotid body. Berlin: Springer-Verlag; 1977. p. 145-51.

207. Sampson SR, Aminoff MJ, Jaffe RA, Vidruk EH. Analysis of inhibitory effect of dopamine on carotid body chemoreceptors in cats. Am J Physiol 1976; 230: 1494-8.

208. Tomares SM, Bamford OS, Sterni LM, Fitzgerald RS, Carroll JL.The role of endogenous dopamine as an inhibitory neuromodulator in neonatal and adult carotid bodies. Adv Exp Med Biol 1994; 360: 321-3.

209. Zapata P. Modulatory role of dopamine on arterial chemoreceptors. Adv Biochem Psychopharmacol 1977; 16: 291-8.

210. Siggins GR. Monoamines and message transduction in central neurons. In Magistretti PJ, Morrisson, JH, Reisine TD, eds. Discussions in Neurosciences. Vol III, transduction of neuronal signals. Amsterdam: Elsevier; 1986. p. 61-8.

211. Nisoli E, Tonello C, Imhof R, Scherschlicht R, da Prada M, Carruba MO. Neurochemical and behavioral evidence that Ro 41-9067 is a selective presynaptic dopamine receptor agonist. J Pharmacol Exp Ther 1993; 266: 97-105.

212. Okajima Y, Nishi K. Analysis of inhibitory and excitatory actions of dopamine on chemoreceptor discharges of carotid body of cat in vivo. Jpn J Physiol 1981; 31: 695704.

213. Lahiri S, Nishino T, Mokashi A, Mulligan E. Interaction of dopamine and haloperidol with $\mathrm{O}_{2}$ and $\mathrm{CO}_{2}$ chemoreception in carotid body. $\mathrm{J}$ Appl Physiol 1980; 49: 45-51.

214. Aminoff MJ, Jaffe RA, Sampson SR, Vidruk EH. Effects of droperidol on activity of carotid body chemoreceptors in cat. Br J Pharmacol 1978; 63: $245-50$.

215. Donnelly DF, Smith EJ, Dutton RE. Neural response of carotid chemoreceptors following dopamine blockade. J Appl Physiol 1981; 50: 172-7.

216. Zapata P, Zuazo A. Reversal of respiratory responses to dopamine after dopamine antagonists. Respir Physiol 1982; 47: 239-55.

217. Zapata P, Serani A, Lavados M. Inhibition in carotid body chemore-

\section{QUIMIORRECEPTORES ARTERIALES: MECANISMOS \\ CELULARES Y MOLECULARES DE LAS FUNCIONES ADAPTATIVA Y HOMEOSTÁTICA DEL CUERPO CAROTÍDEO}

Resumen. El cuerpo carotídeo es un quimiorreceptor sensorial situado cerca de la bifurcación carotídea. Desde el punto de vista estructural, está constituido por islotes celulares formados por dos tipos de células: las células quimiorreceptoras propiamente dichas y las células sustentaculares. Las terminaciones nerviosas sensoriales del nervio del seno carotídeo penetran en dichos islotes y establecen contactos sinápticos con las células quimiorreceptoras. El cuerpo carotídeo desempeña un papel importante en el control de la ventilación durante la hipoxia, la hipercapnia y la acidosis. La hipoxia y los demás estímulos naturales son detectados por las células quimiorreceptoras, a las que estimulan y hacen aumentar su tasa de secreción de neurotransmisores. Dichos neurotransmisores, a su vez, aumentan la frecuencia de potenciales de acción en el nervio del seno carotídeo, el cual, a través de sus proyecciones centrales hacia el tronco del encéfalo, activa la ventilación. La presente revisión se centra en los aspectos celulares de la función de este órgano quimiorreceptor. Partimos de una breve descripción de la estructura del cuerpo carotídeo para presentar seguidamente, de forma resumida, las principales teorías vigentes sobre los mecanismos de transducción para los estímulos hipóxico y ácido/hipercápnico, haciendo un énfasis especial en las propiedades eléctricas de las células quimiorreceptoras en cultivo. Hacemos también una mención especial del posible significado de las especies reactivas de oxígeno como mediadores de la cascada de transducción hipóxica. Se revisa también con cierto detalle la neurotransmisión entre las células quimiorreceptoras y las terminaciones nerviosas sensoriales. Tras una breve reseña histórica de las teorías de comunicación entre dichas estructuras, y siguiendo siempre los criterios clásicos de neurotransmisión, examinamos el significado funcional de la acetilcolina, la dopamina, la sustancia $P$ y otros neurotransmisores que están presentes en las células quimiorreceptoras. [REV NEUROL 2003; 36: 239-54]

Palabras clave. Canales de $\mathrm{K}^{+}$. Cuerpo carotídeo. Dopamina. $\mathrm{Hi}$ poxia. Neurotransmisión. Transducción sensorial. ceptors mediated by D2 dopaminoceptors: antagonism by benzamides. Neurosci Lett 1983; 42: 179-84.

218. Zapata P, Torrealba F. Blockade of dopamine induced chemosensory inhibition by domperidone. Neurosci Lett 1984; 51: 359-64.

219. Iturriaga R, Larrain C, Zapata P. Effects of dopaminergic blockade upon carotid chemosensory activity and its hypoxia-induced excitation. Brain Res 1994; 663: 145-54.

220. Gifford AN, Johnson KM. A pharmacological analysis of the effects of (+)-AJ 76 and (+)-UH 232 at release regulating pre- and postsynaptic dopamine receptors. Eur J Pharmacol. 1993; 237: 169-75.

221. Schoemaker H, Claustre Y, Fage D, Rouquier L, Chergui K, Curet O, et al. Neurochemical characteristics of amisulpride, an atypical dopamine D2/D3 receptor antagonist with both presynaptic and limbic selectivity. J Pharmacol Exp Ther 1997; 280: 83-97.

222. Nolan WF, Donnelly DF, Smith EJ, Dutton RE. Haloperidol induced suppression of carotid chemoreception in vitro. J Appl Physiol 1985; 59: 814-20.

223. McQueen DS, Ribeiro JA. On the specificity and type of receptor involved in carotid body chemoreceptor activation by adenosine in the cat. Br J Pharmacol 1983; 80: 347-54.

224. Ribeiro JA, McQueen DS. Effects of purines on carotid chemoreceptors. In Pallot DJ, ed. The peripheral arterial chemoreceptors. London: Croom Helm; 1994. p. 383-90.

225. Spergel D, Lahiri S. Differential modulation by extracellular ATP of carotid chemosensory responses. J Appl Physiol 1993; 74: 3052-6.

226. Monteiro EC, Ribeiro JA. Ventilatory effects of adenosine mediated by carotid body chemoreceptors in the rat. Naunyn Schmiedebergs Arch Pharmacol 1987; 335: 143-8.

227. Monteiro EC, Ribeiro JA. Adenosine deaminase and adenosine uptake inhibitions facilitate ventilation in rats. Naunyn Schmiedebergs Arch Pharmacol 1989; 340: 230-8.

228. Rocher A, González C, Almaraz L. Adenosine inhibits L-type $\mathrm{Ca}^{2+}$ currents and catecholamine release in the rabbit carotid body chemoreceptor cells. Eur J Neurosci 1999; 11: 673-81.

\section{QUIMIO-RECEPTORES ARTERIAIS: MECANISMOS CELULARES E MOLECULARES DAS FUNÇÕES ADAPTATIVAS E HOMEOSTÁTICAS DO CORPO CAROTÍDEO}

Resumo. O corpo carotídeo é um quimio-receptor sensorial situado na proximidade da bifurcação carotídea. Sob o ponto de vista estrutural, é constituído por ilheus celulares formadas por dois tipos de células: as células quimio-receptoras propriamente ditas e as células sustentaculares. As terminações nervosas sensoriais do nervo do seio carotídeo penetram nos referidos ilheus e estabelecem contactos sinápticos com as células quimio-receptoras. $O$ corpo carotídeo representa um papel importante no controlo da ventilação durante a hipoxia, a hipercapnia e a acidose. A hipoxia e os demais estímulos naturais são detectados pelas células quimio-receptoras, estimulando-as e aumentando o seu índice de secreção de neurotransmissores. Estes neurotransmissores, por sua vez, aumentam a frequência de potenciais de acção no nervo do seio carotídeo, o qual através das suas projecções centrais para o tronco cerebral activa a ventilação. A presente revisão centra-se nos aspectos celulares da função deste órgão quimio-receptor. Partindo de uma breve descrição da estrutura do corpo carotídeo, apresentamos de seguida, de forma resumida, as principais teorias vigentes sobre os mecanismos de transdução para os estímulos hipóxico e ácido/hipercápnico, dando ênfase especial às propriedades eléctricas das células quimio-receptoras em cultura. Fazemos também uma menção especial ao possível significado das espécies reactivas do oxigénio, como mediadores da cascata de transdução hipóxica. É igualmente revista, com certo pormenor a neurotransmissão entre as células quimio-receptoras e as terminações nervosas sensoriais. Após um breve resumo histórica das teorias de comunicação entre as referidas estruturas, e seguindo sempre os critérios clássicos de neurotransmissão, examinamos o significadofuncional da acetilcolina, da dopamina, da substância $P$ $e$ de outros neurotransmissores que estão presentes nas células quimio-receptoras. [REV NEUROL 2003; 36: 239-54]

Palavras chave. Canais de $K^{+}$. Corpo carotídeo. Dopamina. Hipoxia. Neurotransmissão. Transdução sensorial. 